\title{
The role of antigen presentation in tumour-associated macrophages
}

Richard J. Stopforth ${ }^{1 *}$ and E. Sally Ward ${ }^{1 \#}$

${ }^{1}$ Centre for Cancer Immunology

University of Southampton

Faculty of Medicine

SO16 6YD

*․J.Stopforth@soton.ac.uk

\# Correspondence: E.S.Ward@soton.ac.uk 


\begin{abstract}
Macrophages are cells of the myeloid lineage with important roles in immune regulation and tissue repair, but also in pathological states such as autoimmune disease and cancer. A plethora of macrophage subtypes exist with distinct phenotypes and functions, not least within the tumour microenvironment (TME) of solid tumours. The abundant macrophages located within the TME are often referred to as tumour-associated macrophages (TAMs). TAMs may be pro-inflammatory with anti-tumour properties, or may have pro-tumour functions such as angiogenesis. Typically, TAMs are endowed with pro-tumour phenotypes, which has led to strategies to deplete or reprogram TAMs within the TME. Although historically recognised as professional antigen presenting cells (APCs), macrophages are often considered inferior in their abilities to process and present antigen in comparison to dendritic cells (DCs). Notwithstanding, this review gives an overview of the potential accessory role that macrophages might have in antigen processing and presentation to $\mathrm{T}$ cells within the TME, with implications for the design of novel immunotherapies.
\end{abstract}

\title{
Key words
}

Macrophage, Tumour-associated macrophage, Tumour microenvironment, Phagocytosis, Antigen presentation, Major histocompatibility complex, Monoclonal antibody, Immunoglobulin G, Fc gamma receptor, Neonatal Fc receptor 


\section{Introduction}

Elie Metchnikoff can be recognised for his extensive contributions to the early identification and study of macrophages ${ }^{1}$, which are predominantly phagocytic cells of the myeloid lineage with important roles in health and disease. In health, macrophages are responsible for functions such as the clearance of apoptotic cell debris and tissue repair following injury. Alternatively, in disease, macrophages may be aberrantly activated and contribute to tissue damage, such as in the context of various autoimmune diseases. ${ }^{2}$

Macrophages are also particularly abundant within the mass of solid tumours and, considering this, have historically been referred to as TAMs. ${ }^{3-5}$ Further to hypoxia, ${ }^{6}$ various tumour-derived factors in the TME have recently been shown to promote TAM differentiation, including but not limited to lactic acid ${ }^{7}$, succinate ${ }^{8}$, high molecular weight hyaluronic acid ${ }^{9}$ and retinoic acid. ${ }^{10}$ Positive feedback loops also exist, whereby TAMs induced by tumour-derived factors elaborate cytokines and chemokines that either act on TAMs themselves, or on tumour cells, to further promote the TAM phenotype. ${ }^{11}$

TAMs are able to create an immunosuppressive milieu wherein T cells are inhibited, ${ }^{10,12}$ and may also interact with T cells in the stroma to prevent their infiltration into the tumour. ${ }^{13} \mathrm{In}$ addition, they can possess properties that aid the growth or spread of tumours. An example includes the ability of TAMs to produce the chemokine, CCL8, which may both increase cancer cell motility/invasion and contribute to the recruitment of additional TAMs. ${ }^{11}$ Nevertheless, knowledge of TAM functions has led to their therapeutic targeting, with the aim of depleting suppressive TAMs, or re-polarising or -programming them to a phenotype more conducive for effective anti-tumour immune responses. ${ }^{14}$

Macrophages are often described as existing along a spectrum of polarisation states, from classically-activated or pro-inflammatory M1, to alternatively-activated or anti-inflammatory 
M2. Although this nomenclature has received criticism for being oversimplified, ${ }^{15}$ defining macrophages as M1 or M2 is useful in an in vitro setting, as macrophages with M1 or M2 phenotypes can be traditionally polarised with stimuli such as lipopolysaccharide (LPS)/interferon gamma (IFN- $\gamma$ ) or interleukin (IL)-4/IL-13, ${ }^{16}$ respectively, for further study. In the setting of tumours, TAMs are often described as having a pro-tumorigenic M2 phenotype. ${ }^{17}$ However, as discussed herein, it is becoming clear that this is likely to be much more complicated in a tumour setting due, for example, to the presence of mixed subpopulations of macrophages that may share typical M1 or M2 markers.

Much of the focus in the field has been centred on the ability of DCs to induce adaptive immune responses against cancer. ${ }^{18}$ However, macrophages are also professional APCs that have the ability to process and present antigens to T cells. ${ }^{19-24}$ Moreover, TAMs have recently been shown to be capable of presenting tumour antigens to T cells. ${ }^{25,26}$ Therefore, although such functions are less well understood and likely to be less efficient than DCs, the abundance of TAMs within the TME argues that, provided they have the correct phenotype, they may have a role in antigen processing and presentation. In this way, TAMs may induce or re-activate antigen-specific T cells in certain settings, such as in early-stage tumours or following immunotherapy. How to effectively harness these properties of macrophages is of key interest. This review will focus on the potential for macrophages to be involved in antigen processing and presentation to T cells within the TME. Current knowledge concerning the biology of antigen uptake and processing by macrophages will be reviewed. Evidence for antigen presentation by TAMs will also be presented, combined with how novel immunotherapeutic strategies such as the targeting of antigens to macrophages or engineering of macrophages for target recognition may unleash their anti-tumour properties. Finally, unknown aspects of their biology and outstanding questions for the future will be considered. 


\section{TAM subtypes}

Despite the fact that TAMs have been linked to a worse prognosis of tumour patients, it has become evident that tumours may contain a mixture of TAMs bearing M1 or M2 markers, which is important to consider when using TAMs as a biomarker for prognosis. ${ }^{27}$ A recent example is the observation of both M1- and M2-like TAMs in metastatic renal cell carcinoma (RCC). ${ }^{28}$ Moreover, macrophages with anti-tumour properties may be present within a tumour, despite not having a typical M1 or M2 profile. As an example, inflammatory $\left(\mathrm{C}_{\mathrm{Q}} \mathrm{C}^{+}\right)$macrophages with a marked upregulation of expression of major histocompatibility complex (MHC) class II (MHC-II) molecules were identified within human colorectal cancer (CRC) samples. ${ }^{29}$ Four populations of macrophages with similar properties to those of $\mathrm{C} 1 \mathrm{QC}^{+}$macrophages were also identified within mouse tumours. ${ }^{29}$ Such macrophages may have a role in the presentation of antigens to $\mathrm{CD} 4^{+} \mathrm{T}$ cells within the TME. Alternatively, angiogenic $\left(\mathrm{SPP}^{+}\right)$macrophages that did not express antigen-presenting molecules within the same human CRC tumours had an equivalent population within mouse tumours. ${ }^{29}$ Such cells are unlikely to have antigen-processing/presenting functions, but did not have a clear M2 signature. Further still, three populations of TAMs were identified in breast cancer (namely, clusters 23, 25 and 28) that did not have definitive M1 or M2 signatures. ${ }^{30}$ Rather, there appeared to be a positive correlation between the expression of both M1 and M2 genes by TAMs. ${ }^{30}$ Similarly, in early stage lung cancer, TAMs were identified that expressed a mixture of M1 and M2 markers. ${ }^{26}$ Collectively, these studies suggest that there is likely to be a plethora of TAM subtypes present within tumours; that the M1-M2 classification may not always be useful or applicable; that there are likely differences depending on the tumour in question; and that there is still much to learn about the phenotypes and functions of these important cells. 


\section{Acquisition of antigens by macrophages}

How macrophages process and present antigen first requires an understanding of how these cells acquire antigen from the extracellular space. Macrophages are capable of acquiring antigen in various ways, using either receptor- or non-receptor mediated mechanisms, which are briefly detailed in the sections below.

\section{A. Phagocytosis}

Phagocytosis refers to the eating of particles larger than $0.5 \mu \mathrm{m}$ by APCs including macrophages. ${ }^{31}$ Owing to their size, tumour cells fit into this category. A four-step process for phagocytosis has been described which involves the sequential steps of particle recognition, internalisation, phagosome formation and maturation to the phagolysosome. ${ }^{31}$ This culminates in the destruction of the ingested particle. Phagocytosis mediated by macrophages is, in particular, more efficient when targets are coated with opsonins such as antibodies. ${ }^{31}$ In this way, antibody-dependent cell-mediated phagocytosis (ADCP), whereby macrophages engulf tumour cells opsonised with antibodies, is a well-defined function of these cells. ${ }^{32}$ ADCP has been proposed to be a pivotal mechanism of action of direct tumourtargeting therapeutic monoclonal antibodies (mAbs), and has been shown to occur in vivo using intravital microscopy. ${ }^{32-34}$ ADCP is mediated via Fc gamma receptors (Fc $\gamma \mathrm{Rs}$ ) that are abundantly expressed on the surface of macrophages. These receptors bind to their cognate ligands on the opsonised cell, namely the Fc (fragment crystallisable) regions of immunoglobulin G (IgG) molecules. There are 5 activatory Fc $\gamma$ Rs in humans (Fc $\gamma$ RI, IIa, IIc, IIIa and IIIb) and a single inhibitory Fc $\gamma \mathrm{R}$ (Fc $\gamma \mathrm{RIIb}$ ), whereas there are 3 activatory Fc $\gamma \mathrm{Rs}$ in mice (Fc $\gamma \mathrm{RI}$, III and IV) and a single inhibitory Fc $\gamma \mathrm{R}$ (Fc $\gamma \mathrm{RIIb}) .{ }^{35}$ In general, Fc $\gamma \mathrm{RI}$ is known as the single high affinity Fc $\gamma \mathrm{R}$ owing to its unique ability to bind to monomeric IgG with a dissociation constant in the nanomolar range. ${ }^{36}$ However, there are various layers of 
complexity which need to be considered for Fc $\gamma$ R:IgG $(\mathrm{Fc})$ interactions. These include differences in the IgG subclass; IgG glycosylation status; Fc $\gamma \mathrm{R}$ polymorphisms; Fc $\gamma \mathrm{R}$ coexpression; Fc $\gamma R$ expression level and valency of the physiological ligand for Fc $\gamma$ Rs, immune complexes (ICs) comprising antibody and antigen in multimeric form. ${ }^{36-38}$ The expression of Fc $\gamma$ Rs on macrophages is variable depending on tissue location or in vitro culture method. ${ }^{39}$ Nevertheless, macrophages are generally considered to co-express both activatory Fc $\gamma$ Rs and the inhibitory Fc $\gamma$ RIIb, the latter of which has long been known to attenuate the function of the former. ${ }^{40}$ Importantly, the affinity of the Fc region of mAbs to both activatory Fc $\gamma$ Rs and the inhibitory Fc $\gamma \mathrm{RIIb},{ }^{41}$ or the relative expression of the activatory Fc $\gamma$ Rs to inhibitory Fc $\gamma \mathrm{RIIb},{ }^{42,43}$ may alter the activatory:inhibitory (A:I) ratio and therefore the efficiency of effector mechanisms including ADCP. How the Fc region influences Fc $\gamma \mathrm{R}$ effector mechanisms and the efficacy of mAb therapies has been extensively reviewed elsewhere. ${ }^{44-46}$

\section{B. Trogocytosis}

The interaction of the Fc region of an antibody with Fc $\gamma$ Rs on the macrophage cell surface may also lead to engulfment by the macrophage of a portion of the target tumour cell membrane, in the absence of entire cell engulfment. This mechanism is known as trogocytosis (from the Greek word, trogo, meaning to gnaw), a term originally coined almost 20 years ago ${ }^{47}$ to describe observations including the acquisition of molecules such as peptide-MHC complexes by T cells from APCs. ${ }^{48,49}$ Trogocytosis may have differing consequences in the setting of mAb therapy. Firstly, trogocytosis may lead to resistance to some mAb treatments, including anti-CD20 mAbs, by removing available target antigen from the target tumour cell surface, as reviewed elsewhere ${ }^{50}$. In the setting of CD20 mAbs, trogocytosis, also known as "shaving”, has been proposed to occur concomitantly with ongoing phagocytosis, and along with the internalisation of CD20-mAb complexes (so-called modulation) represents a potential complementary mechanism of resistance to anti-CD20 
mAb therapy. ${ }^{51}$ However, macrophage-mediated trogocytosis has been reported to lead to the death of tumour cells opsonised with anti-HER2 mAbs, ${ }^{52}$ indicating that differences may exist depending on the target antigen and/or tumour cell in question. Trogocytosis may also occur in other settings, such as the transfer of MHC class I (MHC-I)-peptide complexes from target cells to DCs. ${ }^{53}$ Whether the latter is relevant to macrophages or TAMs would therefore be interesting to investigate.

\section{Endocytosis}

Endocytosis refers to the receptor-mediated internalisation of an antigen from the cell surface. It is well established that the mannose receptor (MR, CD206), a known M2 macrophage marker, participates in the endocytosis of antigens, ${ }^{21,54}$ as will be discussed below (See 'IV. Antigen processing and presentation by macrophages'). Another example of endocytosis is the internalisation of 'small' ICs (i.e. not highly multivalent) that have bound to surface Fc $\gamma$ Rs. ${ }^{55}$ Monomeric IgG, however, is expected to bind to the high affinity Fc $\gamma$ RI expressed on the surface of macrophages. ${ }^{56}$ Alternatively, IgG in the extracellular fluid that is not bound to cell surface receptors is likely to be taken up by macrophages by pinocytosis, ${ }^{56}$ which is described below.

\section{Pinocytosis}

Macrophages are extremely active in pinocytosis, which can be defined as the receptorindependent, fluid-phase uptake of soluble molecules within pinocytic vesicles. As an example, the uptake of low density lipoprotein by macrophages, resulting in the formation of foam cells due to cholesterol accumulation, is known to occur by pinocytosis. ${ }^{57}$ The rate of macrophage pinocytosis is remarkable, with early estimates indicating that pinocytic vesicles account for $0.43 \%$ of the cell volume after one minute, which equates to uptake of the entire

cell volume within just less than four hours. ${ }^{58}$ Pinocytosis can be defined as micro- or macro- 
pinocytosis depending on the size of the solute and vesicle formed. In this way, $70 \mathrm{kDa}$ dextran has been used in studies of macrophage macropinocytosis. ${ }^{59}$ Moreover, macropinocytosis can be further classified as constitutive or inducible, with the latter occurring in response to growth factors or chemokines. ${ }^{60}$ Notwithstanding, molecules contained within these vesicles are typically directed to lysosomes for degradation or, alternatively, recycled to the cell surface. ${ }^{61,62}$

Although pinocytosis is receptor-independent, interaction with receptors can occur within pinosomes post-uptake. In this regard, the neonatal Fc receptor, FcRn, has an important role to play following the pinocytosis of IgG and albumin molecules. ${ }^{63-65}$ This mechanism is controlled by the $\mathrm{pH}$-dependent binding of IgG and albumin to FcRn ${ }^{66-68}$. In this way, IgG and albumin do not bind to FcRn at extracellular, neutral $\mathrm{pH}$ (7.4), but interact with FcRn as the $\mathrm{pH}$ is lowered to $\sim 6$ within intracellular sorting, or early, endosomes ${ }^{69,70}$. Of relevance here is that the extracellular $\mathrm{pH}$ of solid tumours is known to be acidic. ${ }^{71}$ This suggests that the acidic TME will enhance receptor-mediated uptake of IgG and albumin into intratumoral, FcRn-expressing cells.

In any case, molecules that do not bind to FcRn following uptake into sorting endosomes are destined for degradation in lysosomes ${ }^{69}$. Alternatively, FcRn-bound IgG and albumin may be rescued and subsequently recycled and released by exocytosis into the extracellular fluid ${ }^{72,73}$. This mechanism is known to extend the half-life of antibodies ${ }^{74}$, and such knowledge has led to the development of therapeutic agents to block FcRn, enhance the catabolism of pathogenic autoantibodies, and consequently reduce disease severity ${ }^{75-78}$. Such FcRn targeting has recently been reviewed elsewhere. ${ }^{64}$ Importantly, it has also been shown that FcRn expression by macrophages makes a substantial contribution to the regulation of the half-life of administered antibodies and endogenous IgG levels. ${ }^{79}$ 
Polarised macrophages are known to differ in their rates of pinocytosis, as human M2polarised macrophages have been shown to be more active in this regard. ${ }^{59,80}$ This is thought to reflect the differing functions of polarised macrophages, whereby anti-inflammatory (M2) macrophages have an antigen sampling role, by contrast with the antigen presentation activity of pro-inflammatory (M1) macrophages. ${ }^{60}$ It is unknown how the level of FcRn expression by TAMs influences IgG recycling within tumours. However, it is conceivable that TAMs have a role in the recycling of administered mAb therapies within the TME. In this way, the ratio between TAM pinocytosis and FcRn-mediated rescue from degradation may influence the availability of mAbs at the tumour site with, for example, a highly pinocytic macrophage population with decreased FcRn expression being expected to engage in increased IgG degradation. Hence, the anti-tumour activity of tumour-targeting mAbs might be decreased under these conditions.

\section{Antigen processing and presentation by macrophages}

This section will focus on the known roles of macrophages in antigen processing and presentation to T cells. Comparisons will be made with DCs whenever relevant, as there are interesting differences in the biology of these two cell types, which may help to explain differences in antigen processing and presentation.

\section{A. Antigen cross-presentation by macrophages}

The dogma of antigen presentation dictates that intracellular antigens are processed for presentation on MHC-I molecules to cytotoxic $\mathrm{CD}^{+} \mathrm{T}$ cells, whereas extracellular antigens taken up from outside the cell are processed in the MHC class II compartment (MIIC) ${ }^{81}$ for presentation on MHC-II molecules to helper CD4 ${ }^{+} \mathrm{T}$ cells. The MIIC is not a unique compartment per se, but can be best described as a late endosomal/lysosomal-like compartment that possesses key features that include the presence of the MHC-II-loading 
accessory molecule, HLA-DM, and MHC-II molecules; having an acidic pH and accessibility to antigens; and the ability to transport MHC-II to the cell surface. ${ }^{81}$ In relation to the latter, tubules/vesicles that contain MHC-II and emanate from the MIIC, have been identified in maturing human DCs. ${ }^{82}$

Cross-presentation, on the other hand, refers to the ability of APCs to ingest antigen from the extracellular space, process it and present it on MHC-I molecules for the priming of CD8 ${ }^{+} \mathrm{T}$ cells. ${ }^{83}$ Such antigen-specific $\mathrm{CD}^{+}$cytotoxic $\mathrm{T}$ cells are subsequently able to lyse tumour cells expressing cognate antigen presented on MHC-I molecules. This explains the interest in generating MHC-I-restricted $\mathrm{CD}^{+}{ }^{\mathrm{T}}$ cell responses for the treatment of cancer. ${ }^{84}$

Cross-presentation is normally considered to be a feature characteristic of DCs, especially conventional DC subset 1 (cDC1) DCs ${ }^{83}$. In this way, DCs expressing CD103 (a cDC1 marker in mice), which traffic to the lymph node for the priming of naïve $\mathrm{CD}^{+} \mathrm{T}$ cells, have been shown to be a key feature of the response to immunotherapy in mouse models. ${ }^{85} \mathrm{~A}$ longstanding question has therefore been whether macrophages, like DCs, are capable of crosspresenting exogenous antigen, acquired from outside of the cell, to CD8 ${ }^{+} \mathrm{T}$ cells. Interesting studies of Houde and colleagues showed that macrophages do indeed have this capability, as they were shown to phagocytose Ovalbumin (OVA)-latex particles and cross-present antigen to $\mathrm{CD}^{+}$OT-I cells. ${ }^{19}$ The mechanism identified was proposed to be due to initial enzymemediated digestion of proteins within phagosomes, followed by Sec61-mediated transfer of peptides to the cytosol, further digestion by proteasomes associated with the phagosome membrane, and re-import of peptides to the phagosome by transporter associated with antigen processing (TAP) for presentation on MHC-I. ${ }^{19}$ In fact, the $\mathrm{CD}^{+} \mathrm{T}$ cell proliferation and cytokine secretion observed was TAP-dependent, although it was conceded that, in addition to phagosomal loading, some peptides may enter the endoplasmic reticulum (ER) for binding to MHC-I via this same mechanism ${ }^{19}$. Nevertheless, this is often referred to as the 'cytosolic' 
pathway of antigen cross-presentation. Not all studies have reported a role for the proteasome in antigen processing and cross-presentation by macrophages, ${ }^{20,24}$ however, indicating the presence of different mechanisms. As an example, monocyte-derived macrophages were capable of processing a MelanA long peptide antigen and cross-presentation to HLA-A2restricted $\mathrm{CD}^{+}{ }^{+} \mathrm{T}$ cells as measured by IFN $\gamma$ secretion. ${ }^{20}$ However, this was resistant to inhibition of proteasomal activity by lactacystin, but not by protease (cathepsin) inhibitors. This alternative method of cross-presentation is referred to as the 'vacuolar' pathway, ${ }^{20,24}$ whereby both protease-mediated digestion and peptide loading onto MHC-I occur within endolysosomal compartments, without antigen export to the cytosol. ${ }^{83}$ Experimental differences between studies of cross-presentation pathways, such as antigen uptake mechanism or macrophage source and culture method, may explain these apparently discrepant findings. Nevertheless, it is reasonable to suggest that both pathways can occur depending on the context.

In fact, the antigen uptake mechanism is known to influence downstream antigen processing and presentation to $\mathrm{CD} 4^{+}$or $\mathrm{CD}^{+} \mathrm{T}$ cells. Using OVA as a model antigen, Burgdorf and colleagues demonstrated that in DCs, MR-endocytosed antigen was directed towards MHC-I cross-presentation to $\mathrm{CD}^{+} \mathrm{T}$ cells, whereas pinocytosed antigen was directed towards MHCII presentation to CD4 ${ }^{+}$T cells. $^{21}$ This was true for macrophages, although macrophages could also process scavenger receptor-endocytosed antigen for presentation on MHC-II to CD4 ${ }^{+}$T cells. ${ }^{21}$ Despite these findings, other studies have indicated that pinocytosed antigens are presented on MHC-I molecules and endocytosed antigens on MHC-II, ${ }^{86}$ highlighting a level of complexity that is incompletely understood.

Typically, however, macrophages are considered to be less-efficient cross-presenters in comparison to DCs. There are many potential reasons for this. A study by Pozzi and colleagues showed that macrophages are indeed capable of antigen cross-presentation to 
$\mathrm{CD}^{+} \mathrm{T}$ cells. ${ }^{22}$ Critically, macrophages were less migratory in comparison to DCs in vivo, although macrophages seemingly had a similar or enhanced ability to traffic to the lymph nodes when administered intravenously. ${ }^{22}$ As a result of this, higher levels of antigen were required to prime $\mathrm{T}$ cell responses of a similar magnitude in the setting of macrophages. ${ }^{22}$ However, such intravenous trafficking is unlikely to be relevant in the setting of a tumour.

Other fundamental differences between macrophages and DCs exist, which likely have key consequences for antigen presentation. One such difference is the content of their intracellular vesicles. ${ }^{87}$ In an attempt to explain why DCs are more efficient at antigen presentation, pivotal work by Delamarre and colleagues showed that macrophages were enriched for lysosomal proteases and degraded more antigen in comparison to DCs. ${ }^{87}$ Macrophages therefore rapidly destroy internalised antigens, and are consequently predicted to present fewer antigens and/or different peptide repertoires to T cells. The differing $\mathrm{pH}$ of internal vesicles in these two cell types is also relevant for the discussion of FcRn below (see 'B. FcRn and antigen presentation'). Another variable that could affect their ability to activate T cells could be their differential expression of co-stimulatory molecules. ${ }^{20,88}$ Despite being able to activate a MelanA/HLA-A2-restricted CD8 ${ }^{+}$clone, monocyte-derived macrophages were substantially less active in stimulating allogeneic $\mathrm{CD} 8^{+} \mathrm{T}$ cells to proliferate or secrete IFN $\gamma$ or perforin/Granzyme A in comparison to DCs, although the presence of $\mathrm{CD} 4^{+} \mathrm{T}$ cells did enhance $\mathrm{CD} 8^{+} \mathrm{T}$ cell activation. ${ }^{20}$ This was suggested to be due to differences in co-stimulatory molecule expression and IL-12p70 secretion, ${ }^{20}$ thus representing important factors to consider.

Interestingly, in a comprehensive study by Sugiura and colleagues, thioglycolate-induced peritoneal macrophages expressed less CD80 in comparison to splenic DCs. ${ }^{88}$ It was shown that CD80 interacts with programmed death-ligand 1 (PD-L1) in cis, thus preventing interaction with PD-1 on T cells in trans. ${ }^{88}$ Therefore, if macrophages express lower levels of 
CD80, more PD-L1 may be available to interact with PD-1 on T cells and inhibit their responses, as was indicated. ${ }^{88}$ Comparable PD-L1-mediated inhibition was not observed with DCs, presumably due to their higher expression of CD80. ${ }^{88}$ However, in other studies macrophages, including TAMs, have been shown to express co-stimulatory molecules, ${ }^{26,29}$ indicating that this may not always be a limiting factor. For example, clear CD80 expression on inflammatory $\left(\mathrm{C} 1 \mathrm{QC}^{+}\right)$, but not angiogenic $\left(\mathrm{SPP} 1^{+}\right)$, TAMs was observed. ${ }^{29}$ Similarly, as TAMs appeared to have a mixed phenotype and expressed both co-stimulatory and coinhibitory molecules in the study of Singhal and colleagues, ${ }^{26}$ it may be that the balance of co-stimulatory versus co-inhibitory molecule expression regulates the potential for $\mathrm{T}$ cell activation. Similarly, activation (such as in response to immunotherapy) is likely to change the pattern of co-stimulatory molecule expression by macrophages.

Finally, the argument that DCs cannot be easily distinguished from macrophages in terms of their markers and functions ${ }^{89}$ is relevant to this discussion. Indeed, it has been stated that an “APC is not a cell type; it is a regulated activity" ${ }^{89}$ A recent example of the plasticity of DCs and macrophages is the observation that cDC2 DCs can acquire properties of both cCD1 and macrophages to become “inf-cDC2” cells ${ }^{90}$.

\section{B. FcRn and antigen presentation}

As indicated above, FcRn has a key function in the recycling of IgG and albumin.

Interestingly, it has also been reported to play a role in the regulation of antigen processing and presentation. ${ }^{91}$ Much of the knowledge of the role of FcRn in antigen presentation has resulted from studies using DCs in relation to the cross-presentation of antigen derived from ICs. ${ }^{91-93}$ For example, the use of ICs containing wild-type (WT) Fc regions or Fc regions mutated to ablate FcRn binding indicated that FcRn within $\mathrm{CD}^{-} \mathrm{CD} 11 \mathrm{~b}^{+} \mathrm{DCs}$, as opposed to $\mathrm{CD}^{+} \mathrm{CD} 11 \mathrm{~b}^{-} \mathrm{DCs}$, plays a major role in cross-presentation to OT-I CD8 ${ }^{+} \mathrm{T}$ cells in vivo. ${ }^{92}$ 
Intriguingly, binding to Fc $\gamma \mathrm{Rs}$ was required for cross-presentation, and a mechanism was described whereby ICs bind to Fc $\gamma \mathrm{Rs}$ at neutral $\mathrm{pH}$, are subsequently internalised, and bind to FcRn at acidic $\mathrm{pH}^{92}$ To this end, phagosomes acidified in the setting of beads coated with ICs containing IgG with a WT Fc region, but not a mutated Fc region that cannot interact with FcRn, and antigen appeared resistant to degradation. ${ }^{92}$ Such antigens were seemingly processed via a mechanism requiring phagosomal Sec61, TAP and proteasome processing. ${ }^{92}$

Considering the expression of FcRn by macrophages, and the abundance of macrophages within the TME, it is conceivable that FcRn may have similar roles in antigen presentation within macrophages, and potentially in TAMs within the TME. Using FcRn ${ }^{-/-}$mouse macrophages, Liu and colleagues analysed the role of FcRn within macrophages. ${ }^{23}$ A role for FcRn in the induction of CD4 ${ }^{+} \mathrm{OT}-\mathrm{II}$ responses was shown for macrophages endocytosing OVA-IC and phagocytosing latex OVA-IC. However, in DCs, a contribution of FcRn to the induction of $\mathrm{CD}^{+} \mathrm{OT}$-II responses was only identified following endocytosis of OVA-IC. ${ }^{23}$ The authors explained their findings by comparing the $\mathrm{pH}$ of endosomes and phagosomes in macrophages and DCs: the $\mathrm{pH}$ of endosomes and phagosomes in macrophages was acidic, whereas only the endosomes of DCs had an acidic $\mathrm{pH} .{ }^{23}$ This represents a discrepancy between the findings of Baker and colleagues, where acidification of phagosomes within $\mathrm{CD}^{-} \mathrm{CD} 11 \mathrm{~b}^{+}$DCs was identified, ${ }^{92}$ and likely represents a difference in the DC subsets or antigen studied. Nevertheless, these observations reinforce the concept that FcRn has a function at lower $\mathrm{pH}$, where it is expected to bind to ICs. To this end, it is conceivable that FcRn plays a role in the protection of IC-derived antigens from degradation at acidic $\mathrm{pH}$ in macrophages, as was reported in the case of $\mathrm{CD}^{-} \mathrm{CD} 11 \mathrm{~b}^{+}$DCs mentioned above ${ }^{92}$. Moreover, it is of interest that differences in phagosomal $\mathrm{pH}$ have been identified in human M1 and M2 macrophages. ${ }^{94}$ The phagosomes of M2 macrophages acidified rapidly and displayed faster lysosome fusion. ${ }^{94}$ Alternatively, the phagosomes of M1 macrophages 
retained near neutral $\mathrm{pH}$ and delayed lysosome fusion, partly due to increased activity of NADPH oxidase (NOX2). ${ }^{94}$ Whether a similar distinction exists for subtypes of TAMs would be interesting to determine, as well as any consequent effects on antigen presentation.

Intriguingly, no difference between $\mathrm{WT}$ and $\mathrm{FcRn}^{-/-} \mathrm{DCs}$ or macrophages and the induction of $\mathrm{CD}^{+}$OT-I responses were detected in the analysis of Liu and colleagues, ${ }^{23}$ indicating that FcRn may not be involved in regulating cross-presentation to $\mathrm{CD}^{+} \mathrm{T}$ cell in this setting. This mirrors a previous finding of the absence of a role for FcRn in peritoneal macrophages in cross-presentation. ${ }^{92}$ Similarly, macrophages were only capable of cross-presenting to CD8 ${ }^{+}$ OT-I cells at high concentrations of OVA (and not OVA-IC or latex-OVA-IC), ${ }^{23}$ suggesting that cross-presentation to $\mathrm{CD}^{+} \mathrm{T}$ cells was less efficient than presentation to $\mathrm{CD} 4^{+} \mathrm{T}$ cells. Despite being FcRn-independent, macrophages were capable of cross-presenting antigens in the work by Baker and colleagues, especially following pulsing of activated macrophages with soluble OVA. ${ }^{92}$ Differences between activated and non-activated macrophages were observed, ${ }^{92}$ suggesting that the activation state of macrophages is also an important factor to consider, as indicated above in the setting of co-stimulatory molecule expression, ${ }^{20}$ which would be expected to change on activation.

In summary, although macrophages can present and cross-present antigens, they are less efficient in comparison to DCs. Moreover, although the role of FcRn in antigen presentation by macrophages is less well characterised, this role may be most relevant for the MHC-IIrestricted presentation of antigens to $\mathrm{CD} 4^{+} \mathrm{T}$ cells. However, the abundance of TAMs in the TME makes these cells well-positioned to contribute to the induction of $\mathrm{T}$ cell responses and their antigen processing/presentation functions should not be ignored, as will be discussed in the next section. 


\section{Macrophage antigen presentation within the TME}

Macrophages that possess the machinery required for antigen presentation have been identified within the TME. As an example, RNA sequencing analysis showed that inflammatory $\left(\mathrm{C} 1 \mathrm{QC}^{+}\right)$TAMs displayed an up-regulation of antigen processing and presentation genes in colorectal cancer (CRC). ${ }^{29}$ Similarly, IL-8-low M1 macrophages in metastatic RCC were enriched for MHC gene expression. ${ }^{28}$ Furthermore, as indicated above, TAMs in early stage lung cancer expressed MHC class II and a combination of costimulatory and -inhibitory receptors. ${ }^{26}$ TAMs have also been shown to present antigens in some circumstances. ${ }^{25,26}$ Alternatively, macrophages within tumours may not have the correct phenotype for antigen presentation to T cells. ${ }^{25,95,96}$ As an example, in contrast to inflammatory $\left(\mathrm{C}_{\mathrm{Q}} \mathrm{QC}^{+}\right) \mathrm{TAMs}$ in $\mathrm{CRC}$, angiogenic (SPP1 $\left.{ }^{+}\right)$TAMs were not enriched for expression of genes associated with antigen processing or presentation pathways, and expressed less CD80 on the cell surface. ${ }^{29}$ Both of these scenarios are discussed below.

\section{A. Evidence for antigen presentation by TAMs}

Several studies have shown the cross-presentation of tumour antigens to CD8 ${ }^{+} \mathrm{T}$ cells by macrophages. ${ }^{25,26,97,98}$ As an example, specialised lymphoid tissue macrophages that express CD169, which is also known as Siglec- $1^{99}$, were shown to be particularly efficient in antigen cross-presentation in a tumour setting. ${ }^{98}$ In this mechanism, injected dead tumour cells were phagocytosed by lymph node-resident $\mathrm{CD}_{169^{+}}$macrophages, for cross-presentation to CD8 ${ }^{+}$ T cells. ${ }^{98}$ CD169+ macrophages have also been shown to interact with and transfer antigens to DCs. ${ }^{100}$ Nevertheless, although the above work of Asano and colleagues ${ }^{98}$ did not involve the study of TAMs within the TME, it is of interest that CD169 has been identified to be expressed by pro-tumour TAMs. ${ }^{11}$ Although such TAMs were linked to a poor prognosis of 
breast cancer patients, ${ }^{11}$ whether CD169 has roles in antigen presentation mediated by TAMs would be interesting to determine.

Other studies have shown that macrophages can cross-present model antigens to $\mathrm{CD}^{+} \mathrm{T}$ cells. In the setting of anti-CD47 mAbs, (See 'B. Restriction of antigen presentation by TAMs'), macrophages that phagocytosed OVA-expressing cancer cells were shown to induce OT-I CD8 ${ }^{+}$T cell proliferation in vitro and in vivo, ${ }^{101}$ highlighting a cross-presenting function. Curiously, however, macrophages did not induce CD4 ${ }^{+} \mathrm{T}$ cell responses. ${ }^{101}$ This could indicate that the CD4 epitopes of OVA were destroyed downstream of phagocytosis. Despite these findings, another study indicated that macrophages were less effective in crosspriming $\mathrm{CD}^{+} \mathrm{T}$ cells in comparison to DCs, as measured by IFN $\gamma$ secretion, and that this was not increased by anti-CD47 mAbs. ${ }^{102}$ Similarly, DCs (but not macrophages) were required for tumour regression induced by anti-CD47 mAbs in vivo. ${ }^{102}$ This suggests, as expected, that cross-presentation is less efficient in macrophages in comparison to DCs. However, the tumour cells did not express the whole OVA antigen in this study.

In addition to the above, it is also of interest whether macrophages are capable of presenting de facto tumour antigens in addition to OVA. To this end, Barrio and colleagues cultured human macrophages or DCs with melanoma cells expressing the MART-1 antigen. ${ }^{97}$ They subsequently compared IFN $\gamma$ secretion from a $\mathrm{CD}^{+} \mathrm{T}$ cell clone restricted to the melanoma antigen MART-1 presented by MHC-I (M27) following incubation with macrophages or DCs, and reported similar secretion. ${ }^{97}$ This indicates that macrophages, prepared in this way at least, have the ability to cross-present tumour antigens in vitro. More convincingly, in in vivo settings, Singhal and colleagues recently showed that TAMs isolated from HLA-A2 ${ }^{+}$

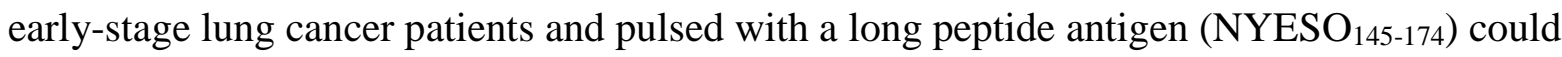
cross-present to an MHC-I-restricted, $\mathrm{CD}^{+}{ }^{+} \mathrm{T}$ cell clone (Ly95), as measured by IFN $\gamma$ 
secretion. ${ }^{26}$ However, variability was observed and TAMs from all donors did not have this capability.

In the context of DCs, a vaccinal effect of mAb therapy has been hypothesised, whereby FcyR-expressing DCs may process and present antigens within ICs that are generated posttherapy. ${ }^{103}$ Considering the link made between FcRn and the cross-presentation of ICs by subtypes of DCs, ${ }^{92}$ it is conceivable that FcRn in DCs may be involved in the processing of ICs comprising therapeutic mAbs bound to tumour antigens. In this regard, it is particularly noteworthy that Baker and colleagues reported a convincing link between FcRn-mediated processing of ICs within DCs and the induction of anti-tumour CD8 ${ }^{+} \mathrm{T}$ cells. ${ }^{93}$ However, whether this occurs in the setting of mAb therapy and/or whether macrophages have a role in this phenomenon are yet to be confirmed. The abundance of TAMs in the TME, that have the ability to express Fc $\gamma$ Rs and MHC molecules (especially when favourably activated), indicates that they may potentially have a role. However, in a tumour setting, it is not fully understood how different antigens are presented by macrophages, and also what occurs downstream of distinct immunotherapies. This raises the question concerning which antigens are presented to $\mathrm{T}$ cells downstream of ADCP, and how Fc-engineering of mAbs to enhance $\mathrm{ADCP}^{104}$ and/or trogocytosis ${ }^{52}$ might influence the repertoire of antigens presented by macrophages. Interestingly, a curious vacuolar compartment was identified within macrophages downstream of ADCP. ${ }^{105}$ The results of this study indicated that the $\mathrm{pH}$ of this compartment is higher than the phagosome, ${ }^{105}$ suggesting that it could represent a less degradative compartment with a role in antigen presentation.

Similarly, it would be interesting to assess the influence on antigen presentation of treatments known to modify the pattern of Fc $\gamma \mathrm{R}$ expression by macrophages, such as STimulator of INterferon Genes (STING) agonists ${ }^{42}$ or cyclophosphamide. ${ }^{43}$ In this way, Roghanian and colleagues showed that cyclophosphamide induces MHC-II and CD86 expression on bone 
marrow (BM) macrophages and up-regulation of an antigen-processing and presentation gene signature, ${ }^{43}$ indicating that these cells may contribute to antigen presentation. However, such roles are yet to be studied in detail.

\section{B. Restriction of antigen presentation by TAMs}

On the other hand, it is important to consider that macrophages within the TME are likely to be less efficient in antigen presentation due to the immunosuppressive milieu. In line with this, TAMs have been shown to suppress T cells. ${ }^{10,12}$

Notably, Kaneda and colleagues showed that phosphatidylinositol-3-kinase gamma (PI3K $\gamma$ ) signalling was responsible for the suppressive phenotype of TAMs. ${ }^{106}$ For example, an increase in MHC-II expression on PI3K $\gamma$-deficient TAMs was identified, ${ }^{106}$ suggesting an antigen presentation defect in WT TAMs. Moreover, in a recent study by Diskin and colleagues, evidence was provided that the antigen presentation ability of macrophages was blocked by PD-L1-expressing T cells. ${ }^{96}$ Firstly, PD-L1-expressing T cells were shown to induce an M2 phenotype in programmed cell death protein 1 (PD-1)-expressing TAMs, both in vitro and in tumour-infiltrating macrophages. ${ }^{96}$ This is of interest, as although PD-1 and PD-L1 are typically expected to be expressed on the reverse cell populations, PD-1 has previously been shown to be expressed by TAMs, with functional consequences on phagocytosis. ${ }^{107}$ Secondly, TAMs expressed a lower percentage of MHC-II within tumours that contain PD-L1-expressing T cells in comparison to PD-L1-deficient T cells, ${ }^{96}$ indicating that they may be less active in antigen presentation to $\mathrm{CD}^{+} \mathrm{T}$ cells. Similarly, macrophages pulsed with OVA peptide induced less activation of PD-L1 ${ }^{+} \mathrm{T}$ cells in comparison to PD-L1tumour T cells. ${ }^{96}$ Although not involving study of a tumour antigen, these analyses indicate that macrophages may have the ability to present antigens within tumours, but that such antigen presentation may be suppressed by PD-L1-expressing T cells. In another example, 
Muraoka and colleagues showed that TAMs from an immunotherapy-resistant fibrosarcoma model (CMS5a) expressed less MHC-II in comparison to treatment-sensitive tumours, ${ }^{25}$ indicating an antigen presentation defect. Moreover, when the ability to present antigens was assessed, TAMs from CMS5a tumours were less able to induce the proliferation of/cytokine secretion by CD8 ${ }^{+} \mathrm{T}$ cells specific for a tumour peptide (DUC18), when compared to TAMs from the treatment-sensitive CMS5a/NYESO tumour. ${ }^{25}$ Nevertheless, these studies clearly show that TAMs from treatment-sensitive tumours are capable of cross-presenting antigens. Macrophages may also have reduced activity in acquiring antigens due to their interaction with ligands expressed by tumour cells. An example of this is tumour expression of CD47 which is known to interact with Signal regulatory protein alpha (SIRP $\alpha$ ) present on the surface of macrophages, resulting in an inhibition of phagocytosis. ${ }^{101,108}$ The suppressive TME is also known to skew the pattern of TAM Fc $\gamma \mathrm{R}$ expression towards the pattern of inhibitory FcyRIIb. This has been shown in contexts such as the BCL 1 lymphoma model ${ }^{42}$ or the resistant $\mathrm{BM}$ niche ${ }^{43}$, and is not amenable to efficient ADCP. Alternatively, suppressive metabolites within the TME may inhibit phagocytosis and downstream antigen processing/presentation. Adenosine is one such example of an abundant metabolite of the TME. ${ }^{109}$ In a recent study, adenosine was shown to inhibit phagocytosis, and the adenosine receptor Adora2a expressed by macrophages was deemed to have an important role in this. ${ }^{95}$ Moreover, a greater number of TAMs expressed the co-stimulatory molecule CD80 and MHC-II in the tumours of Adora2 $\mathrm{a}^{-/-}$mice, ${ }^{95}$ suggesting that these cells may have the capacity to present antigen to $\mathrm{CD}^{+}{ }^{\mathrm{T}}$ helper cells, but that this is inhibited by adenosine. Similarly, there was a greater expansion of $\mathrm{CD}^{+} \mathrm{T}$ cells specific for the model antigen OVA in tumour-bearing Adora2a $\mathrm{a}^{-/-}$mice treated with anti-CD20 mAb. ${ }^{95}$ Nevertheless, another study identified a CD73-expressing TAM population in glioblastoma that was seemingly immune suppressive and contributed to treatment failure. ${ }^{110}$ This is of interest because CD73 
is an enzyme that converts adenosine monophosphate (AMP) to adenosine and, intriguingly, $\mathrm{CD} 3^{-/-}$mice had an increased tumour infiltration of anti-tumour inducible nitric oxide synthase positive (iNOS ${ }^{+}$) macrophages and granzyme $\mathrm{B}^{+} \mathrm{CD}^{+} \mathrm{T}$ cells in response to immunotherapy, in comparison to WT mice. ${ }^{110}$ This further indicates a detrimental role for adenosine.

Conversely, antigen presentation may also have negative consequences for macrophages. To this end, the aforementioned study by Singhal and colleagues indicated that TAMs were able to cross-present antigen on MHC-I molecules, but that this made them a target for cytotoxic $\mathrm{CD}^{+}{ }^{\mathrm{T}}$ cells. ${ }^{26}$ However, the macrophages were protected by an up-regulation of PD-L1 expression. ${ }^{26}$ The reported PD-1 expression by TAMs ${ }^{96,107}$ could presumably also prevent killing by PD-L1 ${ }^{+} \mathrm{T}$ cells. Whether this is a general mechanism that is active within solid tumours other than lung cancer is yet to be determined.

In summary, TAMs have the potential to present antigens to T cells but may be limited in this regard due to the immunosuppressive TME. The balance of M1 to M2 macrophage phenotypes likely dictates the ability of TAMs within the tumour to present antigen in the absence of therapy, which will be discussed below.

\section{Targeting macrophage antigen presentation}

Current cancer immunotherapies are not efficacious in all cancer patients, with a substantial proportion of patients failing to show durable responses, such as in the context of landmark studies involving anti-cytotoxic-T-lymphocyte-associated protein 4 (CTLA-4) $)^{111}$ and/or antiPD- $1^{112}$ mAb treatment. This has led to efforts to improve the efficacy of immunotherapies, which include strategies involving the targeting of TAMs as potential immunotherapies. ${ }^{14}$ These can be broadly categorised as those that involve the depletion of TAMs from the TME, or those that enhance the killing of tumour cells by TAMs. This section will detail potential 
strategies, with a focus on the potential for induction of adaptive immune responses and preclinical studies.

\section{A. TAM depletion}

One approach involves the depletion of TAMs. ${ }^{113-117}$ This is based on the rationale that the removal of suppressive TAMs will limit tumour growth and/or aid tumour attack by other cells of the immune system. Numerous strategies for TAM depletion have been proposed. These include the targeting of macrophage colony stimulating factor 1 receptor (CSF1R) using mAbs, ${ }^{113}$ or kinase inhibitors ${ }^{117}$; the depletion of TAMs with clodronate liposomes ${ }^{116}$; the use of plasmids encoding a pro-apoptotic protein (Bim) encapsulated within folatemodified liposomes to target folate receptor $\beta^{+} \mathrm{TAMs}^{114}$; or the targeting of M2 macrophages with a pro-apoptotic peptide. ${ }^{115}$

However, recent research has cautioned against the use of TAM depletion approaches. As an example, anti-CSF1R mAb therapy in a renal cancer model depleted subpopulations of macrophages with pro-inflammatory, anti-tumour properties, and left pro-angiogenic, protumour macrophages untouched. ${ }^{29}$ The macrophages depleted corresponded to two of the TAM populations, namely mM12 and mM14, that were shown to be similar to inflammatory $\left(\mathrm{C}_{\mathrm{Q}} \mathrm{C}^{+}\right)$human TAMs. ${ }^{29}$ In contrast, mM15, which had a gene expression profile similar to angiogenic (SPP1 ${ }^{+}$) TAMs were not depleted. ${ }^{29}$ This indicates that anti-CSF1R therapy is likely to limit rather than promote antigen presentation or the activation of $\mathrm{T}$ cells, and emphasises the need to target depletion strategies to pro-tumour TAMs. However, this may be particularly challenging, for instance due to the aforementioned presence of TAMs within tumours that express both M1 (anti-tumour) and M2 (pro-tumour) markers. ${ }^{26,30}$ Moreover, TAM depletion will eliminate cells that, when appropriately activated, may have potent antitumour properties. 
Therefore, the remainder of this review will focus on strategies that aim to harness the antitumour properties of TAMs by re-polarising them to anti-tumour phenotypes, rather than their depletion. Several recent approaches targeted towards promoting adaptive immune responses against the tumour are highlighted below and shown schematically in Figure 1.

\section{B. Antigen targeting to macrophages}

As indicated above, TAMs from immunotherapy-resistant fibrosarcomas (CMS5a) were defective in their antigen presentation abilities. ${ }^{25}$ To solve this, Muraoka and colleagues encapsulated a long peptide antigen (LPA; containing an MHC-I-restricted 9-mer peptide)

within cholesteryl pullulan (CHP) nanogels. ${ }^{25}$ Following intravenous treatment, it was shown that such nanogels trafficked to macrophages within the tumour and, when given in combination with the toll-like receptor (TLR) agonist CpG, that TAMs from the tumour could induce the proliferation of $\mathrm{CD}^{+} \mathrm{T}$ cells restricted to the 9-mer peptide (DUC18). ${ }^{25}$ As a treatment, a combination of CHP:LPA nanogel, CpG and naïve CD8 ${ }^{+} \mathrm{T}$ cells (DUC18) led to greater tumour regression than in the absence of long peptide antigen or $\mathrm{CpG} .{ }^{25}$ Finally, in addition to showing that TAMs can present antigens ex vivo, evidence was provided that the macrophages are capable of presenting antigen in vivo. To this end, tumour regression was greater when mice were given intratumoral injections of peptide-pulsed BM-derived macrophages followed by $\mathrm{CD}^{+} \mathrm{T}$ cell adoptive transfer, in comparison to unpulsed macrophages, ${ }^{25}$ indicating that antigen targeting to TAMs is a viable approach.

This considered, it is possible that TAMs can be targeted with antigens using other approaches. As an example, antigens may be targeted to Fc $\gamma$ Rs using antigen-Fc fusions (Figure 1). In addition, strategies to target CD169 may have potential. To this end, Chen and colleagues showed that liposomes could be coated with a sialic acid ligand for CD169/Siglec1 targeting, with consequent binding to mouse and human CD169. ${ }^{118}$ Despite some cross- 
reactivity to mouse Siglec-G, liposomes loaded with OVA and targeted to CD169 were able to induce presentation of peptide to OT-II CD4 ${ }^{+} \mathrm{T}$ cells by BM-derived macrophages, as measured by proliferation. ${ }^{118}$ Considering the reported expression of CD169 by TAMs, ${ }^{11}$ this may represent a strategy to target antigen to TAMs in a cancer setting. In this way, although such TAMs were linked to a worse prognosis in breast cancer, ${ }^{11}$ it is possible that antigen targeting or re-polarisation could skew them to an anti-tumour phenotype. Alternatively, the results of Cruz-Leal and colleagues suggested that macrophages are responsible for crosspresentation to $\mathrm{CD}^{+} \mathrm{T}$ cells following targeting with liposomes encapsulated with OVA and a pore-forming toxin, sticholysin II (StII). ${ }^{24}$ The results also indicated that macrophages may be capable of inducing a cytotoxic $\mathrm{CD}^{+} \mathrm{T}$ cell response in vivo. ${ }^{24}$ An interesting question relates to the role of such liposomes in the setting of a tumour antigen.

\section{Antibody-mediated blockade or repolarisation of TAMs}

Another recently reported strategy involves the targeting of Mer proto-oncogene tyrosine kinase (MerTK)-mediated macrophage efferocytosis, ${ }^{119,120}$ which has been recently reviewed elsewhere. ${ }^{121}$ Efferocytosis refers to the ingestion of apoptotic cells, and this process is known to be profoundly immunosuppressive rather than being permissible for antigen presentation and the induction of anti-tumour immune responses. ${ }^{122}$ In one approach, soluble MerTK inhibitors were tested in breast cancer models, in combination with a small molecule inhibitor (Lapatinib) to induce cancer cell apoptosis. ${ }^{119}$ However, despite blocking efferocytosis, MerTK inhibition resulted in the induction of immune suppression following secondary necrosis, presumably due to the effects of IFN $\gamma$ and downstream indolamine-2,3dioxygenase (IDO) expression. ${ }^{119}$ Nevertheless, a combined MerTK/IDO inhibition approach was effective in tumour models. ${ }^{119}$ In particular, a decreased infiltration of both Foxp $3^{+}$ regulatory $\mathrm{T}$ cells and $\mathrm{LAG3}^{+}$anergic $\mathrm{T}$ cells was noted, indicating the induction of an improved anti-tumour immune response in comparison to MerTK inhibiton alone. ${ }^{119}$ 
More recently, anti-MerTK mAbs have been tested. ${ }^{120}$ It was shown that anti-MerTK mAbs block apoptotic cell uptake by TAMs and induce a type I IFN response, and that anti-MerTK combinations improve responses to anti PD-L1 or anti-PD-1 mAbs in tumour models. ${ }^{120}$ In relation to antigen presentation, using an OVA-expressing MC38 tumour, it was shown that TAMs within tumours presented the immunodominant SIINFEKL epitope on MHC-I molecules. ${ }^{120}$ However, despite $\mathrm{CD}^{+} \mathrm{T}$ cell infiltration being detected, which was required for treatment efficacy, it was shown that $\mathrm{Batf3}^{+}\left(\mathrm{CD}_{103^{+}}\right)$DCs were ultimately required for therapy. ${ }^{120}$ Recently, anti-tumour immune responses were similarly reported to be dependent on $\mathrm{CD}_{103^{+}} \mathrm{DCs}$ in pancreatic cancer tumour models, ${ }^{123}$ thus emphasising their importance. This indicates that TAMs are unlikely to work alone to induce anti-tumour T cell responses, and can potentially be explained by the lesser ability of macrophages to migrate; ${ }^{22,90}$ crosspresent antigens, ${ }^{22,23,90,102}$ such as in the setting of phagocytosed latex bead ICs; ${ }^{23}$ or induce cytotoxic CD8 ${ }^{+}$T cells. ${ }^{20}$ Nevertheless, solid tumours are rich in TAMs but not DCs, with examples including experimental sarcoma tumours ${ }^{10}$ or human melanoma ${ }^{85}$. Therefore, potential facilitating roles of TAMs within the TME cannot be ignored, especially following treatments that polarise them to anti-tumour phenotypes. These may include the initiation of an innate response; the activation of $\mathrm{CD}^{+}$helper T cells via MHC-II; or the re-stimulation of antigen-specific T cells arriving from the lymph nodes.

In addition to MerTK, the targeting of other TAM receptors such as Clever- $1^{124}$ and MARCO $^{125}$ with mAbs has recently been reported, with the aim of re-polarising the TME for anti-tumour immune responses. On the other hand, considering reports of PD-1-expressing TAMs, ${ }^{96,107}$ existing immunotherapy treatments targeting the PD-1/PD-L1 axis may also be effective through targeting TAMs.

Alternative strategies to mAbs have also been tested, with the aim of achieving macrophage repolarisation to anti-tumour phenotypes. ${ }^{14,42,43,106,126}$ As an example, a recent study showed 
that targeting macrophage CD206 (MR) with a 10-mer peptide (RP-182) could induce M2M1 macrophage repolarisation by altering the conformation of CD206 at the cell surface. ${ }^{126}$ Notably, this study showed that RP-182 was capable of inducing an adaptive T cell response to pancreatic tumours, which was seemingly greater in combination with gemcitabine chemotherapy. ${ }^{126}$ This combination also resulted in higher levels of IFN $\gamma$ secretion by $\mathrm{CD} 8^{+}$ T cells when co-cultured with TAMs and tumour cells in an ex vivo assay. ${ }^{126}$ Consistent with this, combination therapy with anti-PD-L1 checkpoint blockade resulted in significantly higher reductions in tumour growth in comparison to single-agent therapy. ${ }^{126}$ These findings may potentially be explained by the induction of tumour antigen-specific $\mathrm{T}$ cells by repolarised TAMs post-phagocytosis and more efficient processing/presentation of antigens by MHC molecules, although this was not formally shown.

Small molecule agonists have also been tested, not limited to those targeting the STING pathway. ${ }^{42}$ Alternatively, immune suppressive pathways in TAMs may be targeted. ${ }^{106}$ In a pivotal study, Kaneda and colleagues showed that inhibition of PI3K $\gamma$ with small molecules synergised with an anti-PD-1 mAb in a head and neck squamous cell carcinoma model, and provided evidence for the induction of an adaptive anti-tumour immune response. ${ }^{106}$ In any case, these studies collectively indicate that TAMs may be targeted with small molecule drugs in addition to mAbs. How such existing and future drugs modulate the ability of TAMs to process and present antigens, and thereby the adaptive immune response, are important and worthwhile factors to consider.

\section{Engineered macrophages}

Another recent strategy involved a more direct manipulation of macrophages. Many studies have focussed on the development of chimeric antigen receptor (CAR) $\mathrm{T}$ cells for the targeting of T cells to cancer cells in an MHC-unrestricted manner, with clinical success 
being observed in the setting of B cell leukaemias rather than solid tumours. ${ }^{127}$ Recently, several groups have also analysed the anti-tumor effects of macrophages that have been transduced to express CAR constructs. ${ }^{128,129}$ For example, in a recent study CAR constructs specific for HER2 were transduced into human macrophages using an adenovirus-based system, in an attempt to develop a treatment for solid tumors. ${ }^{130}$ The resulting macrophages were phagocytic, expressed molecules associated with antigen processing/presentation (including co-stimulatory and MHC molecules), and seemingly had an M1 phenotype. ${ }^{130}$ They also displayed promising in vivo activity in tumour models. ${ }^{130}$ Moreover, donor HLA$\mathrm{A}^{+}$macrophages engineered to express chimeric receptors were able to phagocytose SKOV3 ovarian cancer cells expressing NYESO1, and activate $\mathrm{CD}^{+} \mathrm{T}$ cells expressing a $\mathrm{T}$ cell receptor (TCR) restricted to an NYESO1 peptide, as measured by CD69 upregulation and IFN $\gamma$ secretion. ${ }^{130}$ This indicates that the engineered macrophages are capable of crosspresenting antigens derived from a whole tumour cell, at least in vitro. The authors also suggested that epitope spreading is occurring, because the $\mathrm{CD}^{+} \mathrm{T}$ cells were restricted to a different antigen (NYESO) than that targeted by the CAR construct (HER2). ${ }^{130}$ Finally, this study provided evidence that the engineered macrophages may be able to re-educate suppressive TAMs located within the TME, although further research is required to demonstrate that these cells are capable of priming antigen-specific, endogenous $\mathrm{T}$ cell responses. $^{130}$

\section{Outstanding questions}

This review has provided an overview of macrophages in the setting of tumours, with a particular focus on their possible antigen presentation functions within the TME and the implications of this for therapy. Crucially, TAMs have been shown to cross-present antigens to T cells. Various questions remain, however, not least pertaining to the specific role or 
function of TAMs in the processing and presentation of antigens to T cells within the TME, such as within treatment-sensitive tumours prior to therapy, or in response to immunotherapies that target TAMs. Because of their limited migratory capacity and less efficient cross-presentation by comparison with some populations of DCs, it is conceivable that TAMs may be more efficient in the re-activation of $\mathrm{CD}^{+} \mathrm{T}$ cells that have migrated from lymph nodes, or the activation of $\mathrm{CD}^{+} \mathrm{T}$ helper cells that have infiltrated. In this way, it is likely that TAMs collaborate with DCs to facilitate antigen-specific T cell responses, such as in response to immunotherapy. Moreover, other questions relate to the dominant pathway of antigen uptake within TAMs; the role of FcRn within TAMs; the repertoire of antigenic peptides available following macrophage phagocytosis; and how distinct therapies modulate this. Further still, whether TAMs have increased activity in antigen processing and presentation in the setting of potentially immunogenic tumours that have not yet escaped immune control, for example by downregulating MHC class I expression, ${ }^{123}$ is a crucial question. However, what is clear is that this is an exciting time for the modulation of TAMs for their antigen processing and presentation activities and potential immunostimulatory effects. 


\section{Acknowledgements}

This work was supported in part by the Wellcome Trust (grant number: 206411/Z/17/Z). This review was written in memory of our dear friend and colleague, Eli Sercarz. Eli’s contribution to the field of antigen presentation is monumental: he introduced bold new concepts, including epitope crypticity and determinant spreading, that have been widely adopted in immunology. Further, Eli carried out landmark studies in multiple other immunological areas. Eli’s generosity of spirit, energy and inquisitive intellect, combined with his enthusiasm for karaoke, were also legendary. Discussions with him would be punctuated by creative ideas at every possible juncture. Were he still with us, he would undoubtedly be enchanted by the way in which his inspirational work has formed the foundation for the modulation of $\mathrm{T}$ cell responses in the rapidly expanding field of immunotherapy. 


\section{References}

1. Gordon S. Elie Metchnikoff, the man and the myth. J Innate Immun. 2016;8(3):223-7.

2. Ma WT, Gao F, Gu K, Chen DK. The role of monocytes and macrophages in autoimmune diseases: a comprehensive review. Front Immunol. 2019;10:1140.

3. Mantovani A, Polentarutti N, Peri G, Shavit ZB, Vecchi A, Bolis G, Mangioni C. Cytotoxicity on tumor cells of peripheral blood monocytes and tumor-associated macrophages in patients with ascites ovarian tumors. J Natl Cancer Inst. 1980;64(6):1307-15.

4. Mantovani A. Tumor-associated macrophages. Curr Opin Immunol. 1989;2(5):689-92.

5. Mantovani A, Bottazzi B, Colotta F, Sozzani S, Ruco L. The origin and function of tumorassociated macrophages. Immunol Today. 1992;13(7):265-70.

6. Henze AT, Mazzone M. The impact of hypoxia on tumor-associated macrophages. J Clin Invest. 2016;126(10):3672-79.

7. Colegio OR, Chu NQ, Szabo AL, Chu T, Rhebergen AM, Jairam V, Cyrus N, Brokowski CE, Eisenbarth SC, Phillips GM, Cline GW, Phillips AJ, Medzhitov R. Functional polarization of tumour-associated macrophages by tumour-derived lactic acid. Nature. 2014;513(7519):559-63.

8. Wu JY, Huang TW, Hsieh YT, Wang YF, Yen CC, Lee GL, Yeh CC, Peng YJ, Kuo YY, Wen HT, Lin HC, Hsiao CW, Wu KK, Kung HJ, Hsu YJ, Kuo CC. Cancer-derived succinate promotes macrophage polarization and cancer metastasis via succinate receptor. Mol Cell. 2020;77(2):213-27 e5.

9. Goossens P, Rodriguez-Vita J, Etzerodt A, Masse M, Rastoin O, Gouirand V, Ulas T, Papantonopoulou O, Van Eck M, Auphan-Anezin N, Bebien M, Verthuy C, Vu Manh TP, Turner M, Dalod M, Schultze JL, Lawrence T. Membrane cholesterol efflux drives tumor-associated macrophage reprogramming and tumor progression. Cell Metab. 2019;29(6):1376-89 e4.

10. Devalaraja S, To TKJ, Folkert IW, Natesan R, Alam MZ, Li M, Tada Y, Budagyan K, Dang MT, Zhai L, Lobel GP, Ciotti GE, Eisinger-Mathason TSK, Asangani IA, Weber K, Simon MC, Haldar M. Tumor-derived retinoic acid regulates intratumoral monocyte differentiation to promote immune suppression. Cell. 2020;180(6):1098114 e16. 
11. Cassetta L, Fragkogianni S, Sims AH, Swierczak A, Forrester LM, Zhang H, Soong DYH, Cotechini T, Anur P, Lin EY, Fidanza A, Lopez-Yrigoyen M, Millar MR, Urman A, Ai Z, Spellman PT, Hwang ES, Dixon JM, Wiechmann L, Coussens LM, Smith HO, Pollard JW. Human tumor-associated macrophage and monocyte transcriptional landscapes reveal cancer-specific reprogramming, biomarkers, and therapeutic targets. Cancer Cell. 2019;35(4):588-602 e10.

12. Doedens AL, Stockmann C, Rubinstein MP, Liao D, Zhang N, DeNardo DG, Coussens LM, Karin M, Goldrath AW, Johnson RS. Macrophage expression of hypoxiainducible factor- 1 alpha suppresses T-cell function and promotes tumor progression. Cancer Res. 2010;70(19):7465-75.

13. Peranzoni E, Lemoine J, Vimeux L, Feuillet V, Barrin S, Kantari-Mimoun C, Bercovici N, Guerin M, Biton J, Ouakrim H, Regnier F, Lupo A, Alifano M, Damotte D, Donnadieu E. Macrophages impede CD8 T cells from reaching tumor cells and limit the efficacy of anti-PD-1 treatment. Proc Natl Acad Sci U S A. 2018;115(17):E4041E50.

14. van Dalen FJ, van Stevendaal M, Fennemann FL, Verdoes M, Ilina O. Molecular repolarisation of tumour-associated macrophages. Molecules. 2018;24(1).

15. Nahrendorf M, Swirski FK. Abandoning M1/M2 for a network model of macrophage function. Circ Res. 2016;119(3):414-7.

16. Huang X, Li Y, Fu M, Xin HB. Polarizing macrophages in vitro. Methods Mol Biol. 2018;1784:119-26.

17. Sica A, Schioppa T, Mantovani A, Allavena P. Tumour-associated macrophages are a distinct M2 polarised population promoting tumour progression: potential targets of anti-cancer therapy. Eur J Cancer. 2006;42(6):717-27.

18. Wculek SK, Cueto FJ, Mujal AM, Melero I, Krummel MF, Sancho D. Dendritic cells in cancer immunology and immunotherapy. Nat Rev Immunol. 2020;20(1):7-24.

19. Houde M, Bertholet S, Gagnon E, Brunet S, Goyette G, Laplante A, Princiotta MF, Thibault P, Sacks D, Desjardins M. Phagosomes are competent organelles for antigen cross-presentation. Nature. 2003;425(6956):402-6.

20. Tang-Huau TL, Gueguen P, Goudot C, Durand M, Bohec M, Baulande S, Pasquier B, Amigorena S, Segura E. Human in vivo-generated monocyte-derived dendritic cells and macrophages cross-present antigens through a vacuolar pathway. Nat Commun. 2018;9(1):2570. 
21. Burgdorf S, Kautz A, Bohnert V, Knolle PA, Kurts C. Distinct pathways of antigen uptake and intracellular routing in CD4 and CD8 T cell activation. Science. 2007;316(5824):612-6.

22. Pozzi LA, Maciaszek JW, Rock KL. Both dendritic cells and macrophages can stimulate naive CD8 T cells in vivo to proliferate, develop effector function, and differentiate into memory cells. J Immunol. 2005;175(4):2071-81.

23. Liu X, Lu L, Yang Z, Palaniyandi S, Zeng R, Gao LY, Mosser DM, Roopenian DC, Zhu $\mathrm{X}$. The neonatal FcR-mediated presentation of immune-complexed antigen is associated with endosomal and phagosomal $\mathrm{pH}$ and antigen stability in macrophages and dendritic cells. J Immunol. 2011;186(8):4674-86.

24. Cruz-Leal Y, Grubaugh D, Nogueira CV, Lopetegui-Gonzalez I, Del Valle A, Escalona F, Laborde RJ, Alvarez C, Fernandez LE, Starnbach MN, Higgins DE, Lanio ME. The vacuolar pathway in macrophages plays a major role in antigen cross-presentation induced by the pore-forming protein sticholysin II encapsulated into liposomes. Front Immunol. 2018;9:2473.

25. Muraoka D, Seo N, Hayashi T, Tahara Y, Fujii K, Tawara I, Miyahara Y, Okamori K, Yagita H, Imoto S, Yamaguchi R, Komura M, Miyano S, Goto M, Sawada SI, Asai A, Ikeda H, Akiyoshi K, Harada N, Shiku H. Antigen delivery targeted to tumorassociated macrophages overcomes tumor immune resistance. J Clin Invest. 2019;129(3):1278-94.

26. Singhal S, Stadanlick J, Annunziata MJ, Rao AS, Bhojnagarwala PS, O'Brien S, Moon EK, Cantu E, Danet-Desnoyers G, Ra HJ, Litzky L, Akimova T, Beier UH, Hancock WW, Albelda SM, Eruslanov EB. Human tumor-associated monocytes/macrophages and their regulation of T cell responses in early-stage lung cancer. Sci Transl Med. 2019;11(479).

27. Jayasingam SD, Citartan M, Thang TH, Mat Zin AA, Ang KC, Ch'ng ES. Evaluating the polarization of tumor-associated macrophages into M1 and M2 phenotypes in human cancer tissue: technicalities and challenges in routine clinical practice. Front Oncol. 2019;9:1512.

28. Yuen KC, Liu LF, Gupta V, Madireddi S, Keerthivasan S, Li C, Rishipathak D, Williams P, Kadel EE, 3rd, Koeppen H, Chen YJ, Modrusan Z, Grogan JL, Banchereau R, Leng N, Thastrom A, Shen X, Hashimoto K, Tayama D, van der Heijden MS, Rosenberg JE, McDermott DF, Powles T, Hegde PS, Huseni MA, Mariathasan S. High systemic and tumor-associated IL-8 correlates with reduced clinical benefit of PD-L1 blockade. Nat Med. 2020;26(5):693-98. 
29. Zhang L, Li Z, Skrzypczynska KM, Fang Q, Zhang W, O'Brien SA, He Y, Wang L, Zhang Q, Kim A, Gao R, Orf J, Wang T, Sawant D, Kang J, Bhatt D, Lu D, Li CM, Rapaport AS, Perez K, Ye Y, Wang S, Hu X, Ren X, Ouyang W, Shen Z, Egen JG, Zhang Z, Yu X. Single-cell analyses inform mechanisms of myeloid-targeted therapies in colon cancer. Cell. 2020;181(2):442-59 e29.

30. Azizi E, Carr AJ, Plitas G, Cornish AE, Konopacki C, Prabhakaran S, Nainys J, Wu K, Kiseliovas V, Setty M, Choi K, Fromme RM, Dao P, McKenney PT, Wasti RC, Kadaveru K, Mazutis L, Rudensky AY, Pe'er D. Single-cell map of diverse immune phenotypes in the breast tumor microenvironment. Cell. 2018;174(5):1293-308 e36.

31. Rosales C, Uribe-Querol E. Phagocytosis: a fundamental process in immunity. Biomed Res Int. 2017;2017:9042851.

32. Gul N, van Egmond M. Antibody-dependent phagocytosis of tumor cells by macrophages: a potent effector mechanism of monoclonal antibody therapy of cancer. Cancer Res. 2015;75(23):5008-13.

33. Gul N, Babes L, Siegmund K, Korthouwer R, Bogels M, Braster R, Vidarsson G, ten Hagen TL, Kubes P, van Egmond M. Macrophages eliminate circulating tumor cells after monoclonal antibody therapy. J Clin Invest. 2014;124(2):812-23.

34. Montalvao F, Garcia Z, Celli S, Breart B, Deguine J, Van Rooijen N, Bousso P. The mechanism of anti-CD20-mediated B cell depletion revealed by intravital imaging. J Clin Invest. 2013;123(12):5098-103.

35. Nimmerjahn F, Ravetch JV. Fcgamma receptors as regulators of immune responses. Nat Rev Immunol. 2008;8(1):34-47.

36. Bruhns P, Iannascoli B, England P, Mancardi DA, Fernandez N, Jorieux S, Daeron M. Specificity and affinity of human Fcgamma receptors and their polymorphic variants for human IgG subclasses. Blood. 2009;113(16):3716-25.

37. Lux A, Yu X, Scanlan CN, Nimmerjahn F. Impact of immune complex size and glycosylation on IgG binding to human FcgammaRs. J Immunol. 2013;190(8):431523.

38. Robinett RA, Guan N, Lux A, Biburger M, Nimmerjahn F, Meyer AS. Dissecting FcgammaR regulation through a multivalent binding model. Cell Syst. 2018;7(1):4148 e5.

39. Bruggeman CW, Houtzager J, Dierdorp B, Kers J, Pals ST, Lutter R, van Gulik T, den Haan JMM, van den Berg TK, van Bruggen R, Kuijpers TW. Tissue-specific 
expression of IgG receptors by human macrophages ex vivo. PLoS One. 2019;14(10):e0223264.

40. Clynes RA, Towers TL, Presta LG, Ravetch JV. Inhibitory Fc receptors modulate in vivo cytotoxicity against tumor targets. Nat Med. 2000;6(4):443-6.

41. Nimmerjahn F, Ravetch JV. Divergent immunoglobulin g subclass activity through selective Fc receptor binding. Science. 2005;310(5753):1510-2.

42. Dahal LN, Dou L, Hussain K, Liu R, Earley A, Cox KL, Murinello S, Tracy I, Forconi F, Steele AJ, Duriez PJ, Gomez-Nicola D, Teeling JL, Glennie MJ, Cragg MS, Beers SA. STING activation reverses lymphoma-mediated resistance to antibody immunotherapy. Cancer Res. 2017;77(13):3619-31.

43. Roghanian A, Hu G, Fraser C, Singh M, Foxall RB, Meyer MJ, Lees E, Huet H, Glennie MJ, Beers SA, Lim SH, Ashton-Key M, Thirdborough SM, Cragg MS, Chen J. Cyclophosphamide enhances cancer antibody immunotherapy in the resistant bone marrow niche by modulating macrophage FcgammaR expression. Cancer Immunol Res. 2019;7(11):1876-90.

44. Dahal LN, Roghanian A, Beers SA, Cragg MS. FcgammaR requirements leading to successful immunotherapy. Immunol Rev. 2015;268(1):104-22.

45. Chenoweth AM, Wines BD, Anania JC, Mark Hogarth P. Harnessing the immune system via FcgammaR function in immune therapy: a pathway to next-gen mAbs. Immunol Cell Biol. 2020;98(4):287-304.

46. Nimmerjahn F, Gordan S, Lux A. FcgammaR dependent mechanisms of cytotoxic, agonistic, and neutralizing antibody activities. Trends Immunol. 2015;36(6):325-36.

47. Joly E, Hudrisier D. What is trogocytosis and what is its purpose? Nat Immunol. 2003;4(9):815.

48. Hudrisier D, Riond J, Mazarguil H, Gairin JE, Joly E. Cutting edge: CTLs rapidly capture membrane fragments from target cells in a TCR signaling-dependent manner. $\mathrm{J}$ Immunol. 2001;166(6):3645-9.

49. Huang JF, Yang Y, Sepulveda H, Shi W, Hwang I, Peterson PA, Jackson MR, Sprent J, Cai Z. TCR-mediated internalization of peptide-MHC complexes acquired by $\mathrm{T}$ cells. Science. 1999;286(5441):952-4. 
50. Taylor RP, Lindorfer MA. Analyses of CD20 monoclonal antibody-mediated tumor cell killing mechanisms: rational design of dosing strategies. Mol Pharmacol. 2014;86(5):485-91.

51. Dahal LN, Huang CY, Stopforth RJ, Mead A, Chan K, Bowater JX, Taylor MC, Narang P, Chan HTC, Kim JH, Vaughan AT, Forconi F, Beers SA. Shaving is an epiphenomenon of type I and II anti-CD20-mediated phagocytosis, whereas antigenic modulation limits type I monoclonal antibody efficacy. J Immunol.

2018;201(4):1211-21.

52. Velmurugan R, Challa DK, Ram S, Ober RJ, Ward ES. Macrophage-mediated trogocytosis leads to death of antibody-opsonized tumor cells. Mol Cancer Ther. 2016;15(8):1879-89.

53. Zhang QJ, Li XL, Wang D, Huang XC, Mathis JM, Duan WM, Knight D, Shi R, Glass J, Zhang DQ, Eisenbach L, Jefferies WA. Trogocytosis of MHC-I/peptide complexes derived from tumors and infected cells enhances dendritic cell cross-priming and promotes adaptive T cell responses. PLoS One. 2008;3(8):e3097.

54. Burgdorf S, Lukacs-Kornek V, Kurts C. The mannose receptor mediates uptake of soluble but not of cell-associated antigen for cross-presentation. J Immunol. 2006;176(11):6770-6.

55. Molfetta R, Quatrini L, Gasparrini F, Zitti B, Santoni A, Paolini R. Regulation of fc receptor endocytic trafficking by ubiquitination. Front Immunol. 2014;5:449.

56. Toh WH, Louber J, Mahmoud IS, Chia J, Bass GT, Dower SK, Verhagen AM, Gleeson PA. FcRn mediates fast recycling of endocytosed albumin and IgG from early macropinosomes in primary macrophages. J Cell Sci. 2019;133(5).

57. Kruth HS. Receptor-independent fluid-phase pinocytosis mechanisms for induction of foam cell formation with native low-density lipoprotein particles. Curr Opin Lipidol. 2011;22(5):386-93.

58. Steinman RM, Brodie SE, Cohn ZA. Membrane flow during pinocytosis. A stereologic analysis. J Cell Biol. 1976;68(3):665-87.

59. Redka DS, Gutschow M, Grinstein S, Canton J. Differential ability of proinflammatory and anti-inflammatory macrophages to perform macropinocytosis. Mol Biol Cell. 2018;29(1):53-65. 
60. Doodnauth SA, Grinstein S, Maxson ME. Constitutive and stimulated macropinocytosis in macrophages: roles in immunity and in the pathogenesis of atherosclerosis. Philos Trans R Soc Lond B Biol Sci. 2019;374(1765):20180147.

61. Dolat L, Spiliotis ET. Septins promote macropinosome maturation and traffic to the lysosome by facilitating membrane fusion. J Cell Biol. 2016;214(5):517-27.

62. Racoosin EL, Swanson JA. Macropinosome maturation and fusion with tubular lysosomes in macrophages. J Cell Biol. 1993;121(5):1011-20.

63. Pyzik M, Rath T, Lencer WI, Baker K, Blumberg RS. FcRn: the architect behind the immune and nonimmune functions of IgG and albumin. J Immunol. 2015;194(10):4595-603.

64. Ward ES, Ober RJ. Targeting FcRn to generate antibody-based therapeutics. Trends Pharmacol Sci. 2018;39(10):892-904.

65. Andersen JT, Daba MB, Sandlie I. FcRn binding properties of an abnormal truncated analbuminemic albumin variant. Clin Biochem. 2010;43(4-5):367-72.

66. Raghavan M, Gastinel LN, Bjorkman PJ. The class I major histocompatibility complex related Fc receptor shows $\mathrm{pH}$-dependent stability differences correlating with immunoglobulin binding and release. Biochemistry. 1993;32(33):8654-60.

67. Kim JK, Tsen MF, Ghetie V, Ward ES. Localization of the site of the murine IgG1 molecule that is involved in binding to the murine intestinal Fc receptor. Eur $\mathrm{J}$ Immunol. 1994;24(10):2429-34.

68. Chaudhury C, Mehnaz S, Robinson JM, Hayton WL, Pearl DK, Roopenian DC, Anderson CL. The major histocompatibility complex-related Fc receptor for IgG (FcRn) binds albumin and prolongs its lifespan. J Exp Med. 2003;197(3):315-22.

69. Ober RJ, Martinez C, Vaccaro C, Zhou J, Ward ES. Visualizing the site and dynamics of IgG salvage by the MHC class I-related receptor, FcRn. J Immunol. 2004;172(4):2021-9.

70. Schmidt EGW, Hvam ML, Antunes F, Cameron J, Viuff D, Andersen B, Kristensen NN, Howard KA. Direct demonstration of a neonatal Fc receptor (FcRn)-driven endosomal sorting pathway for cellular recycling of albumin. J Biol Chem. 2017;292(32):13312-22. 
71. Kato Y, Ozawa S, Miyamoto C, Maehata Y, Suzuki A, Maeda T, Baba Y. Acidic extracellular microenvironment and cancer. Cancer Cell Int. 2013;13(1):89.

72. Ober RJ, Martinez C, Lai X, Zhou J, Ward ES. Exocytosis of IgG as mediated by the receptor, FcRn: an analysis at the single-molecule level. Proc Natl Acad Sci U S A. 2004;101(30):11076-81.

73. Grevys A, Nilsen J, Sand KMK, Daba MB, Oynebraten I, Bern M, McAdam MB, Foss S, Schlothauer T, Michaelsen TE, Christianson GJ, Roopenian DC, Blumberg RS, Sandlie I, Andersen JT. A human endothelial cell-based recycling assay for screening of FcRn targeted molecules. Nat Commun. 2018;9(1):621.

74. Ghetie V, Popov S, Borvak J, Radu C, Matesoi D, Medesan C, Ober RJ, Ward ES. Increasing the serum persistence of an IgG fragment by random mutagenesis. Nat Biotechnol. 1997;15(7):637-40.

75. Vaccaro C, Zhou J, Ober RJ, Ward ES. Engineering the Fc region of immunoglobulin G to modulate in vivo antibody levels. Nat Biotechnol. 2005;23(10):1283-8.

76. Kiessling P, Lledo-Garcia R, Watanabe S, Langdon G, Tran D, Bari M, Christodoulou L, Jones E, Price G, Smith B, Brennan F, White I, Jolles S. The FcRn inhibitor rozanolixizumab reduces human serum IgG concentration: a randomized phase 1 study. Sci Transl Med. 2017;9(414).

77. Howard JF, Jr., Bril V, Burns TM, Mantegazza R, Bilinska M, Szczudlik A, Beydoun S, Garrido F, Piehl F, Rottoli M, Van Damme P, Vu T, Evoli A, Freimer M, Mozaffar T, Ward ES, Dreier T, Ulrichts P, Verschueren K, Guglietta A, de Haard H, Leupin N, Verschuuren J, Efgartigimod MGSG. Randomized phase 2 study of FcRn antagonist efgartigimod in generalized myasthenia gravis. Neurology. 2019;92(23):e2661-e73.

78. Blumberg LJ, Humphries JE, Jones SD, Pearce LB, Holgate R, Hearn A, Cheung J, Mahmood A, Del Tito B, Graydon JS, Stolz LE, Bitonti A, Purohit S, de Graaf D, Kacena K, Andersen JT, Christianson GJ, Roopenian DC, Hubbard JJ, Gandhi AK, Lasseter K, Pyzik M, Blumberg RS. Blocking FcRn in humans reduces circulating IgG levels and inhibits IgG immune complex-mediated immune responses. Sci Adv. 2019;5(12):eaax9586.

79. Challa DK, Wang X, Montoyo HP, Velmurugan R, Ober RJ, Ward ES. Neonatal Fc receptor expression in macrophages is indispensable for IgG homeostasis. MAbs. 2019;11(5):848-60. 
80. Montaner LJ, da Silva RP, Sun J, Sutterwala S, Hollinshead M, Vaux D, Gordon S. Type 1 and type 2 cytokine regulation of macrophage endocytosis: differential activation by IL-4/IL-13 as opposed to IFN-gamma or IL-10. J Immunol. 1999;162(8):4606-13.

81. Neefjes J. CIIV, MIIC and other compartments for MHC class II loading. Eur J Immunol. 1999;29(5):1421-5.

82. Barois N, de Saint-Vis B, Lebecque S, Geuze HJ, Kleijmeer MJ. MHC class II compartments in human dendritic cells undergo profound structural changes upon activation. Traffic. 2002;3(12):894-905.

83. Embgenbroich M, Burgdorf S. Current concepts of antigen cross-presentation. Front Immunol. 2018;9:1643.

84. Maher J, Davies ET. Targeting cytotoxic T lymphocytes for cancer immunotherapy. Br J Cancer. 2004;91(5):817-21.

85. Salmon H, Idoyaga J, Rahman A, Leboeuf M, Remark R, Jordan S, Casanova-Acebes M, Khudoynazarova M, Agudo J, Tung N, Chakarov S, Rivera C, Hogstad B, Bosenberg M, Hashimoto D, Gnjatic S, Bhardwaj N, Palucka AK, Brown BD, Brody J, Ginhoux F, Merad M. Expansion and activation of CD103(+) dendritic cell progenitors at the tumor site enhances tumor responses to therapeutic PD-L1 and BRAF inhibition. Immunity. 2016;44(4):924-38.

86. Peppelenbosch MP, DeSmedt M, Pynaert G, van Deventer SJ, Grooten J. Macrophages present pinocytosed exogenous antigen via MHC class I whereas antigen ingested by receptor-mediated endocytosis is presented via MHC class II. J Immunol. 2000;165(4):1984-91.

87. Delamarre L, Pack M, Chang H, Mellman I, Trombetta ES. Differential lysosomal proteolysis in antigen-presenting cells determines antigen fate. Science. 2005;307(5715):1630-4.

88. Sugiura D, Maruhashi T, Okazaki IM, Shimizu K, Maeda TK, Takemoto T, Okazaki T. Restriction of PD-1 function by cis-PD-L1/CD80 interactions is required for optimal T cell responses. Science. 2019;364(6440):558-66.

89. Hume DA. Macrophages as APC and the dendritic cell myth. J Immunol. 2008;181(9):5829-35.

90. Bosteels C, Neyt K, Vanheerswynghels M, van Helden MJ, Sichien D, Debeuf N, De Prijck S, Bosteels V, Vandamme N, Martens L, Saeys Y, Louagie E, Lesage M, Williams DL, Tang SC, Mayer JU, Ronchese F, Scott CL, Hammad H, Guilliams M, 
Lambrecht BN. Inflammatory type 2 cDCs acquire features of cDC1s and macrophages to orchestrate immunity to respiratory virus infection. Immunity. 2020 May 20. Epub 2020 May 4.

91. Baker K, Rath T, Pyzik M, Blumberg RS. The role of FcRn in antigen presentation. Front Immunol. 2014;5:408.

92. Baker K, Qiao SW, Kuo TT, Aveson VG, Platzer B, Andersen JT, Sandlie I, Chen Z, de Haar C, Lencer WI, Fiebiger E, Blumberg RS. Neonatal Fc receptor for IgG (FcRn) regulates cross-presentation of IgG immune complexes by CD8-CD11b+ dendritic cells. Proc Natl Acad Sci U S A. 2011;108(24):9927-32.

93. Baker K, Rath T, Flak MB, Arthur JC, Chen Z, Glickman JN, Zlobec I, Karamitopoulou E, Stachler MD, Odze RD, Lencer WI, Jobin C, Blumberg RS. Neonatal Fc receptor expression in dendritic cells mediates protective immunity against colorectal cancer. Immunity. 2013;39(6):1095-107.

94. Canton J, Khezri R, Glogauer M, Grinstein S. Contrasting phagosome $\mathrm{pH}$ regulation and maturation in human M1 and M2 macrophages. Mol Biol Cell. 2014;25(21):3330-41.

95. Nakamura K, Casey M, Oey H, Vari F, Stagg J, Gandhi MK, Smyth MJ. Targeting an adenosine-mediated "don't eat me signal" augments anti-lymphoma immunity by antiCD20 monoclonal antibody. Leukemia. 2020 May 18. Epub 2020 Apr 8.

96. Diskin B, Adam S, Cassini MF, Sanchez G, Liria M, Aykut B, Buttar C, Li E, Sundberg B, Salas RD, Chen R, Wang J, Kim M, Farooq MS, Nguy S, Fedele C, Tang KH, Chen T, Wang W, Hundeyin M, Rossi JAK, Kurz E, Haq MIU, Karlen J, Kruger E, Sekendiz Z, Wu D, Shadaloey SAA, Baptiste G, Werba G, Selvaraj S, Loomis C, Wong KK, Leinwand J, Miller G. PD-L1 engagement on T cells promotes selftolerance and suppression of neighboring macrophages and effector T cells in cancer. Nat Immunol. 2020;21(4):442-54.

97. Barrio MM, Abes R, Colombo M, Pizzurro G, Boix C, Roberti MP, Gelize E, RodriguezZubieta M, Mordoh J, Teillaud JL. Human macrophages and dendritic cells can equally present MART-1 antigen to CD8(+) T cells after phagocytosis of gammairradiated melanoma cells. PLoS One. 2012;7(7):e40311.

98. Asano K, Nabeyama A, Miyake Y, Qiu CH, Kurita A, Tomura M, Kanagawa O, Fujii S, Tanaka M. CD169-positive macrophages dominate antitumor immunity by crosspresenting dead cell-associated antigens. Immunity. 2011;34(1):85-95.

99. Martinez-Pomares L, Gordon S. CD169+ macrophages at the crossroads of antigen presentation. Trends Immunol. 2012;33(2):66-70. 
100. Grabowska J, Lopez-Venegas MA, Affandi AJ, den Haan JMM. CD169(+) macrophages capture and dendritic cells instruct: the interplay of the gatekeeper and the general of the immune system. Front Immunol. 2018;9:2472.

101. Tseng D, Volkmer JP, Willingham SB, Contreras-Trujillo H, Fathman JW, Fernhoff NB, Seita J, Inlay MA, Weiskopf K, Miyanishi M, Weissman IL. Anti-CD47 antibody-mediated phagocytosis of cancer by macrophages primes an effective antitumor T-cell response. Proc Natl Acad Sci U S A. 2013;110(27):11103-8.

102. Liu X, Pu Y, Cron K, Deng L, Kline J, Frazier WA, Xu H, Peng H, Fu YX, Xu MM. CD47 blockade triggers T cell-mediated destruction of immunogenic tumors. Nat Med. 2015;21(10):1209-15.

103. DiLillo DJ, Ravetch JV. Differential Fc-receptor engagement drives an anti-tumor vaccinal effect. Cell. 2015;161(5):1035-45.

104. Richards JO, Karki S, Lazar GA, Chen H, Dang W, Desjarlais JR. Optimization of antibody binding to FcgammaRIIa enhances macrophage phagocytosis of tumor cells. Mol Cancer Ther. 2008;7(8):2517-27.

105. Velmurugan R, Ramakrishnan S, Kim M, Ober RJ, Ward ES. Phagocytosis of antibodyopsonized tumor cells leads to the formation of a discrete vacuolar compartment in macrophages. Traffic. 2018;19(4):273-84.

106. Kaneda MM, Messer KS, Ralainirina N, Li H, Leem CJ, Gorjestani S, Woo G, Nguyen AV, Figueiredo CC, Foubert P, Schmid MC, Pink M, Winkler DG, Rausch M, Palombella VJ, Kutok J, McGovern K, Frazer KA, Wu X, Karin M, Sasik R, Cohen EE, Varner JA. PI3Kgamma is a molecular switch that controls immune suppression. Nature. 2016;539(7629):437-42.

107. Gordon SR, Maute RL, Dulken BW, Hutter G, George BM, McCracken MN, Gupta R, Tsai JM, Sinha R, Corey D, Ring AM, Connolly AJ, Weissman IL. PD-1 expression by tumour-associated macrophages inhibits phagocytosis and tumour immunity. Nature. 2017;545(7655):495-99.

108. Willingham SB, Volkmer JP, Gentles AJ, Sahoo D, Dalerba P, Mitra SS, Wang J, Contreras-Trujillo H, Martin R, Cohen JD, Lovelace P, Scheeren FA, Chao MP, Weiskopf K, Tang C, Volkmer AK, Naik TJ, Storm TA, Mosley AR, Edris B, Schmid SM, Sun CK, Chua MS, Murillo O, Rajendran P, Cha AC, Chin RK, Kim D, Adorno M, Raveh T, Tseng D, Jaiswal S, Enger PO, Steinberg GK, Li G, So SK, Majeti R, Harsh GR, van de Rijn M, Teng NN, Sunwoo JB, Alizadeh AA, Clarke MF, Weissman IL. The CD47-signal regulatory protein alpha (SIRPa) interaction is a therapeutic target for human solid tumors. Proc Natl Acad Sci U S A. 2012;109(17):6662-7. 
109. Blay J, White TD, Hoskin DW. The extracellular fluid of solid carcinomas contains immunosuppressive concentrations of adenosine. Cancer Res. 1997;57(13):2602-5.

110. Goswami S, Walle T, Cornish AE, Basu S, Anandhan S, Fernandez I, Vence L, Blando J, Zhao H, Yadav SS, Ott M, Kong LY, Heimberger AB, de Groot J, Sepesi B, Overman M, Kopetz S, Allison JP, Pe'er D, Sharma P. Immune profiling of human tumors identifies CD73 as a combinatorial target in glioblastoma. Nat Med. 2020;26(1):39-46.

111. Hodi FS, O'Day SJ, McDermott DF, Weber RW, Sosman JA, Haanen JB, Gonzalez R, Robert C, Schadendorf D, Hassel JC, Akerley W, van den Eertwegh AJ, Lutzky J, Lorigan P, Vaubel JM, Linette GP, Hogg D, Ottensmeier CH, Lebbe C, Peschel C, Quirt I, Clark JI, Wolchok JD, Weber JS, Tian J, Yellin MJ, Nichol GM, Hoos A, Urba WJ. Improved survival with ipilimumab in patients with metastatic melanoma. N Engl J Med. 2010;363(8):711-23.

112. Larkin J, Hodi FS, Wolchok JD. Combined nivolumab and ipilimumab or monotherapy in untreated melanoma. N Engl J Med. 2015;373(13):1270-1.

113. Ries CH, Cannarile MA, Hoves S, Benz J, Wartha K, Runza V, Rey-Giraud F, Pradel LP, Feuerhake F, Klaman I, Jones T, Jucknischke U, Scheiblich S, Kaluza K, Gorr IH, Walz A, Abiraj K, Cassier PA, Sica A, Gomez-Roca C, de Visser KE, Italiano A, Le Tourneau C, Delord JP, Levitsky H, Blay JY, Ruttinger D. Targeting tumorassociated macrophages with anti-CSF-1R antibody reveals a strategy for cancer therapy. Cancer Cell. 2014;25(6):846-59.

114. Tie Y, Zheng H, He Z, Yang J, Shao B, Liu L, Luo M, Yuan X, Liu Y, Zhang X, Li H, Wu M, Wei X. Targeting folate receptor beta positive tumor-associated macrophages in lung cancer with a folate-modified liposomal complex. Signal Transduct Target Ther. 2020;5:6.

115. Lee C, Jeong H, Bae Y, Shin K, Kang S, Kim H, Oh J, Bae H. Targeting of M2-like tumor-associated macrophages with a melittin-based pro-apoptotic peptide. J Immunother Cancer. 2019;7(1):147.

116. Zeisberger SM, Odermatt B, Marty C, Zehnder-Fjallman AH, Ballmer-Hofer K, Schwendener RA. Clodronate-liposome-mediated depletion of tumour-associated macrophages: a new and highly effective antiangiogenic therapy approach. Br J Cancer. 2006;95(3):272-81.

117. Dammeijer F, Lievense LA, Kaijen-Lambers ME, van Nimwegen M, Bezemer K, Hegmans JP, van Hall T, Hendriks RW, Aerts JG. Depletion of tumor-associated macrophages with a CSF-1R kinase inhibitor enhances antitumor immunity and survival induced by DC immunotherapy. Cancer Immunol Res. 2017;5(7):535-46. 
118. Chen WC, Kawasaki N, Nycholat CM, Han S, Pilotte J, Crocker PR, Paulson JC. Antigen delivery to macrophages using liposomal nanoparticles targeting sialoadhesin/CD169. PLoS One. 2012;7(6):e39039.

119. Werfel TA, Elion DL, Rahman B, Hicks DJ, Sanchez V, Gonzales-Ericsson PI, Nixon MJ, James JL, Balko JM, Scherle PA, Koblish HK, Cook RS. Treatment-induced tumor cell apoptosis and secondary necrosis drive tumor progression in the residual tumor microenvironment through MerTK and IDO1. Cancer Res. 2019;79(1):171-82.

120. Zhou Y, Fei M, Zhang G, Liang WC, Lin W, Wu Y, Piskol R, Ridgway J, McNamara E, Huang H, Zhang J, Oh J, Patel JM, Jakubiak D, Lau J, Blackwood B, Bravo DD, Shi Y, Wang J, Hu HM, Lee WP, Jesudason R, Sangaraju D, Modrusan Z, Anderson KR, Warming S, Roose-Girma M, Yan M. Blockade of the phagocytic receptor MerTK on tumor-associated macrophages enhances P2X7R-dependent STING activation by tumor-derived cGAMP. Immunity. 2020;52(2):357-73 e9.

121. Myers KV, Amend SR, Pienta KJ. Targeting Tyro3, Axl and MerTK (TAM receptors): implications for macrophages in the tumor microenvironment. Mol Cancer. 2019;18(1):94.

122. Vaught DB, Stanford JC, Cook RS. Efferocytosis creates a tumor microenvironment supportive of tumor survival and metastasis. Cancer Cell Microenviron. 2015;2(1).

123. Yamamoto K, Venida A, Yano J, Biancur DE, Kakiuchi M, Gupta S, Sohn ASW, Mukhopadhyay S, Lin EY, Parker SJ, Banh RS, Paulo JA, Wen KW, Debnath J, Kim GE, Mancias JD, Fearon DT, Perera RM, Kimmelman AC. Autophagy promotes immune evasion of pancreatic cancer by degrading MHC-I. Nature. 2020;581(7806):100-05.

124. Viitala M, Virtakoivu R, Tadayon S, Rannikko J, Jalkanen S, Hollmen M. Immunotherapeutic blockade of macrophage clever-1 reactivates the CD8(+) T-cell response against immunosuppressive tumors. Clin Cancer Res. 2019;25(11):3289303.

125. Georgoudaki AM, Prokopec KE, Boura VF, Hellqvist E, Sohn S, Ostling J, Dahan R, Harris RA, Rantalainen M, Klevebring D, Sund M, Brage SE, Fuxe J, Rolny C, Li F, Ravetch JV, Karlsson MC. Reprogramming tumor-associated macrophages by antibody targeting inhibits cancer progression and metastasis. Cell Rep. 2016;15(9):2000-11.

126. Jaynes JM, Sable R, Ronzetti M, Bautista W, Knotts Z, Abisoye-Ogunniyan A, Li D, Calvo R, Dashnyam M, Singh A, Guerin T, White J, Ravichandran S, Kumar P, Talsania K, Chen V, Ghebremedhin A, Karanam B, Bin Salam A, Amin R, Odzorig T, Aiken T, Nguyen V, Bian Y, Zarif JC, de Groot AE, Mehta M, Fan L, Hu X, 
Simeonov A, Pate N, Abu-Asab M, Ferrer M, Southall N, Ock CY, Zhao Y, Lopez H, Kozlov S, de Val N, Yates CC, Baljinnyam B, Marugan J, Rudloff U. Mannose receptor (CD206) activation in tumor-associated macrophages enhances adaptive and innate antitumor immune responses. Sci Transl Med. 2020;12(530).

127. Zhao L, Cao YJ. Engineered T cell therapy for cancer in the clinic. Front Immunol. 2019;10:2250.

128. Morrissey MA, Williamson AP, Steinbach AM, Roberts EW, Kern N, Headley MB, Vale RD. Chimeric antigen receptors that trigger phagocytosis. Elife. 2018;7.

129. Zhang W, Liu L, Su H, Liu Q, Shen J, Dai H, Zheng W, Lu Y, Zhang W, Bei Y, Shen P. Chimeric antigen receptor macrophage therapy for breast tumours mediated by targeting the tumour extracellular matrix. Br J Cancer. 2019;121(10):837-45.

130. Klichinsky M, Ruella M, Shestova O, Lu XM, Best A, Zeeman M, Schmierer M, Gabrusiewicz K, Anderson NR, Petty NE, Cummins KD, Shen F, Shan X, Veliz K, Blouch K, Yashiro-Ohtani Y, Kenderian SS, Kim MY, O'Connor RS, Wallace SR, Kozlowski MS, Marchione DM, Shestov M, Garcia BA, June CH, Gill S. Human chimeric antigen receptor macrophages for cancer immunotherapy. Nat Biotechnol. 2020 May 18. Epub 2020 Mar 23. 


\section{Figure}

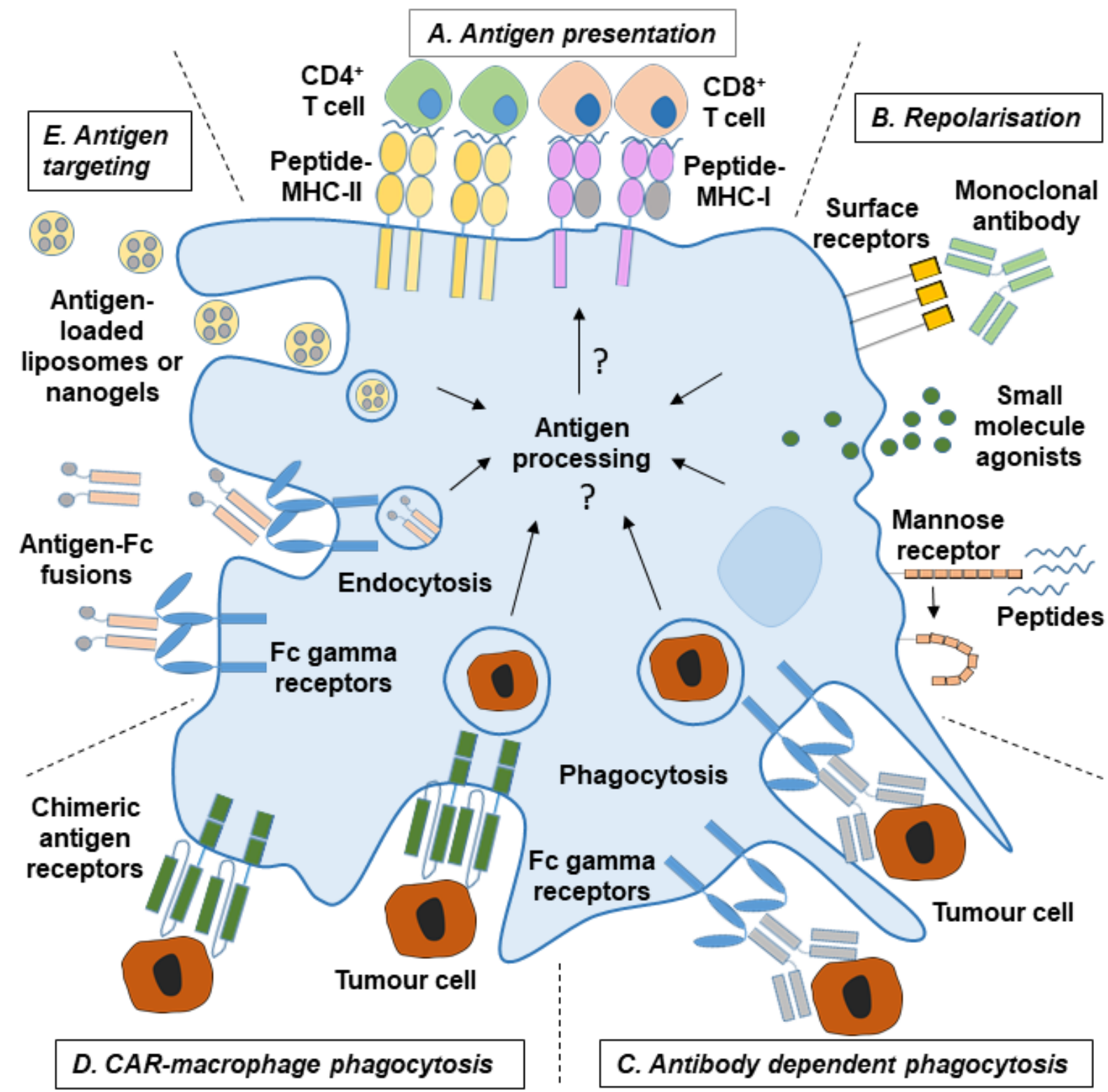

Figure 1. Potential strategies to enhance antigen processing, presentation and the

induction of adaptive immune responses by TAMs. A) A macrophage is depicted, presenting peptide antigens on MHC-II molecules to CD4 ${ }^{+} \mathrm{T}$ cells, or MHC-I molecules to CD8 ${ }^{+} \mathrm{T}$ cells. The T cell TCRs are not shown. B) Repolarisation modalities include the targeting of macrophage receptors with mAbs to inhibit suppressive pathways (i.e. anti-MerTK blockade of efferocytosis); treatment with soluble agonists of intracellular signalling pathways (i.e. STING agonists), or peptides that change the conformation of the mannose receptor (CD206) and re-polarise macrophages (i.e RP-182). 
C) Antibody-dependent cell-mediated phagocytosis (ADCP) of tumour cells opsonised with tumourtargeting mAbs. ADCP has the potential to provide antigens for processing and presentation, and can be optimised by various means (i.e. Fc engineering to increase mAb binding to activatory Fc $\gamma$ Rs over the inhibitory FcyRIIb). Not shown for clarity: Fc $\gamma$ RIIb expression by the macrophage, and trogocytosis. The latter can remove membrane antigens from the target cell in the absence of whole cell uptake. D) Phagocytosis of tumour cells by macrophages engineered to express CARs on their cell surface. E) Antigen targeting to macrophages via antigen-loaded liposomes or nanogels, and antigen-Fc fusions. All of these strategies, may influence antigen processing and presentation, although the precise mechanisms are yet to be elucidated. The processes shown may not be mutually exclusive. For example, transduction of macrophages to express CARs (D) may induce an 'M1' phenotype, and such CAR macrophages may repolarise TAMs in vivo (B); macrophage repolarisation strategies (B) may enhance phagocytosis (C) or antigen processing/presentation (A); and phagocytosis (C and D) may provide antigens to macrophages for downstream processing and presentation (A). 